\title{
A COMPARISON OF NEEDLE-FREE AND NEEDLE INJECTION METHODS AND SOLUTIONS FOR ENHANCEMENT OF BEEF LONGISSIMUS LUMBORUM MUSCLES
}

by

BRETT ALAN CROW

B.S., Kansas State University, 2007

\begin{abstract}
A THESIS
submitted in partial fulfillment of the requirements for the degree

MASTER OF SCIENCE

Department of Animal Sciences and Industry

College of Agriculture
\end{abstract}

\section{KANSAS STATE UNIVERSITY \\ Manhattan, Kansas}

2009

Approved by:

Major Professor

Michael E. Dikeman 


\begin{abstract}
Objectives were to determine the effects of needle-free (NF) versus needle (N) injection methods and/or solutions for enhancement of beef longissimus lumborum muscle (LM) on color, instrumental tenderness, sensory attributes, pump yields, and cooking losses. In experiment $1, \mathrm{LM}(\mathrm{n}=15)$ at $9 \mathrm{~d}$ postmortem were halved before random assignment to $\mathrm{N}$ or $\mathrm{NF}$ injection enhancement with a solution containing $2.2 \%$ salt, $4.4 \%$ sodium tripolyphosphate (STPP), and 1.5\% K lactate. Different steaks from each loin half were either placed on a $5 \mathrm{~d}$ color display, frozen for later sensory analysis, or aged until d 13 postmortem for LM slice shear force measurements. Pump yields tended $(\mathrm{P}=0.08)$ to be higher for NF injection. Needle injected steaks were darker $(\mathrm{P}<0.05)$ on day 1 , but not after that. Discoloration was not different $(\mathrm{P}>0.05)$ between treatments. The NF treatment had greater $(\mathrm{P}<0.05)$ instrumental tenderness and intensity of off-flavors but less $(\mathrm{P}<0.05)$ cooking loss and beef flavor. In Experiment 2, LM $(n=28)$ at $5 \mathrm{~d}$ postmortem were halved before random assignment to one of four treatments: 1) $\mathrm{N}$, or 2) $\mathrm{NF}$ injection with a solution containing $2.2 \%$ salt, $4.4 \% \mathrm{STPP}$, $15 \% \mathrm{~K}$ lactate, and $0.58 \%$ rosemary; 3) N, or 4) NF injection with a solution containing $2.4 \%$ Ca lactate and $0.58 \%$ rosemary. Steaks from each loin half were either frozen for later sensory analysis or aged until d 14 postmortem for LM slice shear force measurements. Loins phosphate enhanced with the NF injector had the highest $(\mathrm{P}<0.05)$ pumped yields with no differences $(\mathrm{P}>0.05)$ among other treatment combinations.

Instrumental tenderness was not different $(\mathrm{P}>0.05)$ between $\mathrm{N}$ and $\mathrm{NF}$ treatments but was higher with the phosphate solution than the Ca lactate solution. The NF treatment had lower $(\mathrm{P}<0.05)$ cooking losses when the phosphate solution was used, which resulted in less $(\mathrm{P}<0.05)$ cooking loss than the Ca lactate solution. More $(\mathrm{P}<0.05)$ off-flavors and abnormal texture resulted from NF injection. The phosphate solution resulted in greater $(\mathrm{P}<0.05)$ myofibrillar and overall tenderness, juiciness, off-flavors and abnormal texture with less $(\mathrm{P}<0.05)$ connective tissue than the Ca lactate solution. Enhancing beef LM
\end{abstract}


with a phosphate solution and NF injection might improve yields, tenderness, and juiciness while harming texture and flavor. 


\section{Table of Contents}

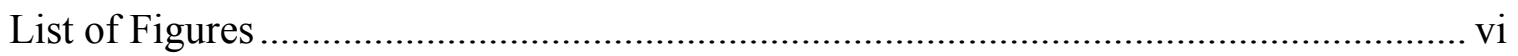

Acknowledgements ............................................................................................. vii

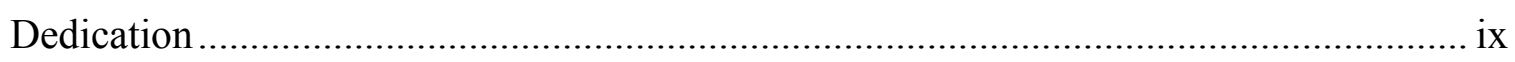

CHAPTER 1 - Literature Review ......................................................................... 1

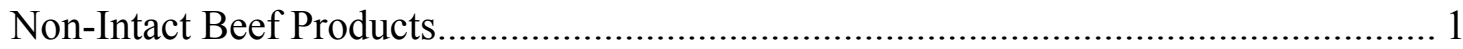

Injection Enhancement of Meat........................................................................ 1

Effects on Instrumental Tenderness and Sensory Traits ........................................... 1

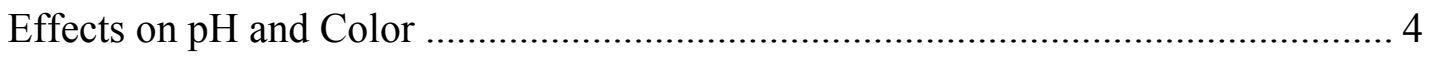

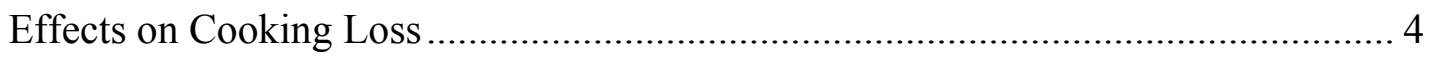

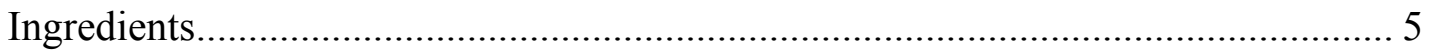

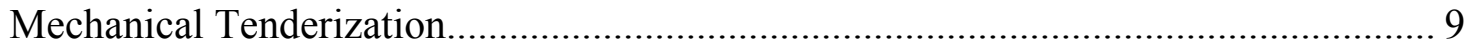

Vaccinating Livestock with a Needle-Free Injector ..................................................... 13

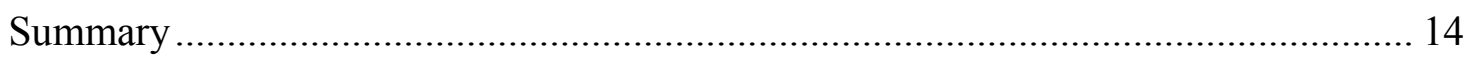

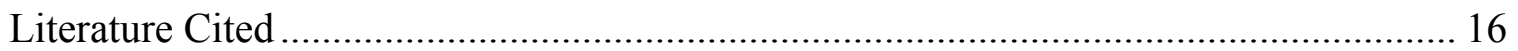

CHAPTER 2 - A Comparison of Needle-Free and Needle Injection Methods and Solutions for Enhancement of Beef Longissimus Lumborum Muscles ............................. 21

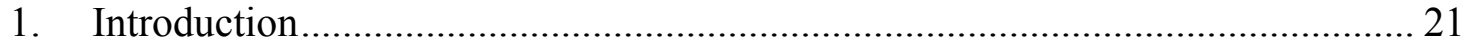

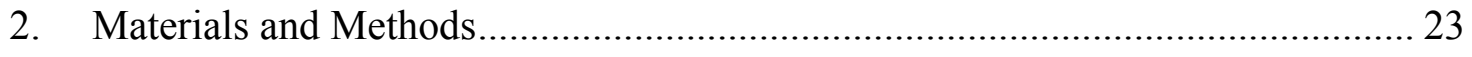

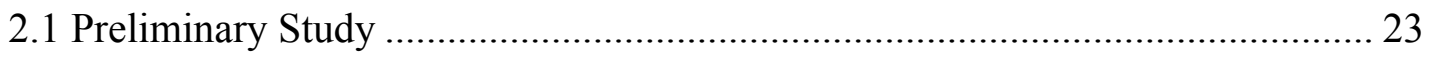

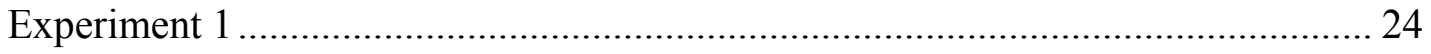

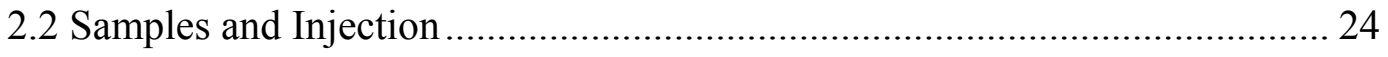

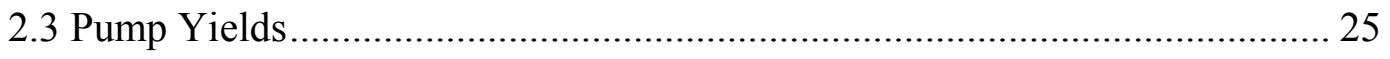

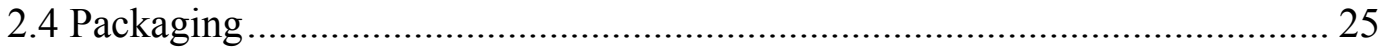

2.5 Display Case and Color Measurements ...................................................... 26

2.6 Longissimus Slice Shear Force Measurements.............................................. 26

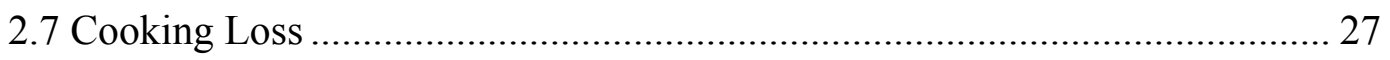

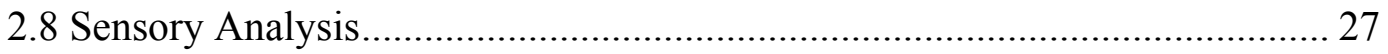

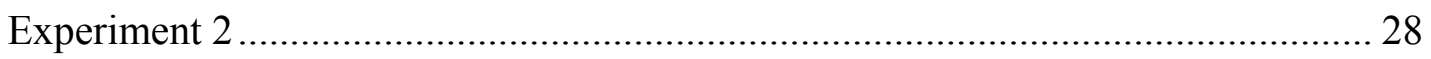




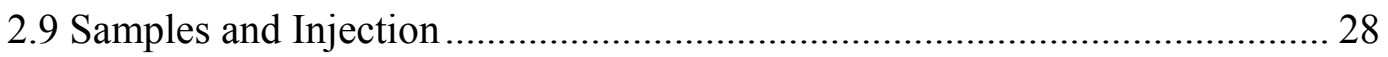

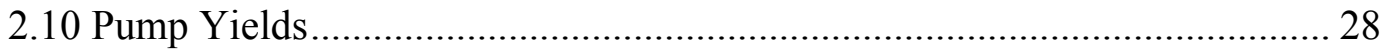

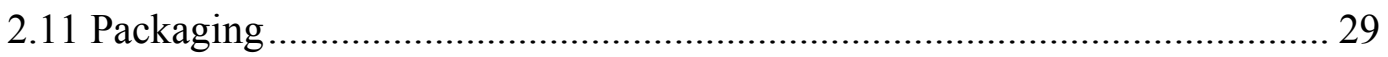

2.12 Longissimus Slice Shear Force Measurements.......................................... 29

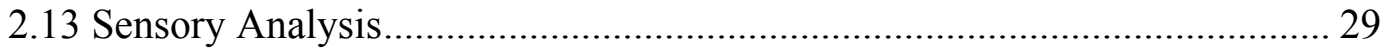

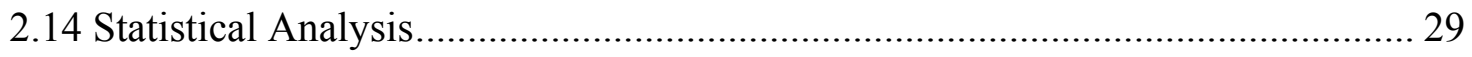

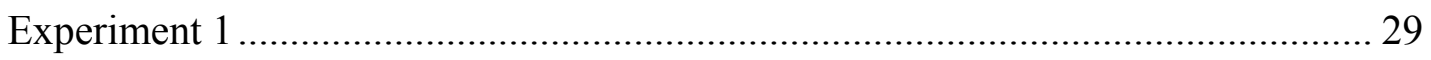

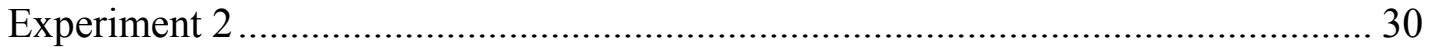

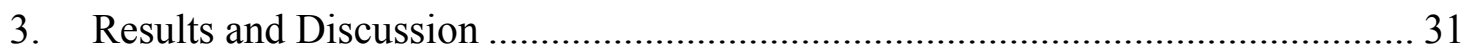

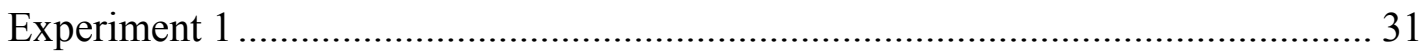

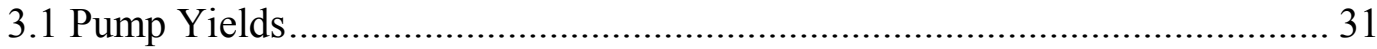

3.2 Display Color and Discoloration ............................................................ 32

3.3 Longissimus Lumborum (LL) Slice Shear Force Measurements .................... 35

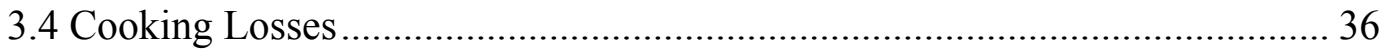

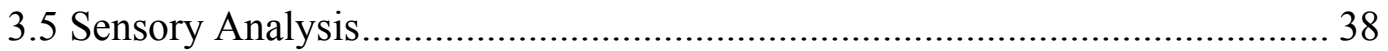

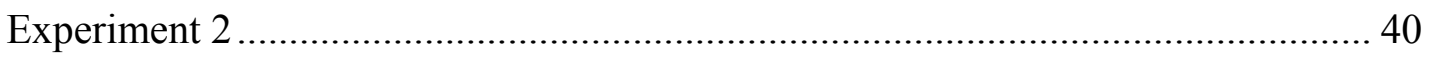

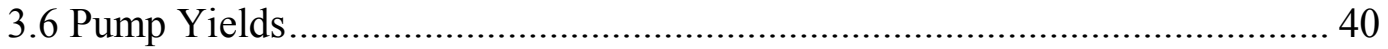

3.7 Longissimus Lumborum (LL) Slice Shear Force Measurements ................... 41

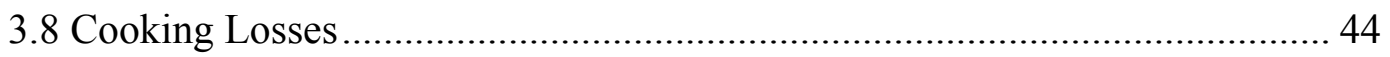

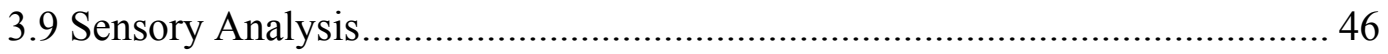

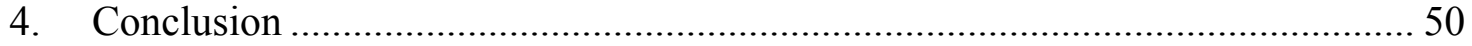

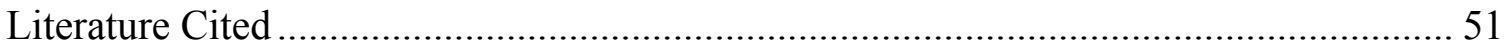




\section{List of Figures}

Fig. 2.1 Photographs illustrating penetration and distribution of the sterile dye............. 24

Fig. 2.2 Pump yield for injection methods used ........................................................ 31

Fig. 2.3 Initial (day 0) color score means for longissimus lumborum steaks for injection

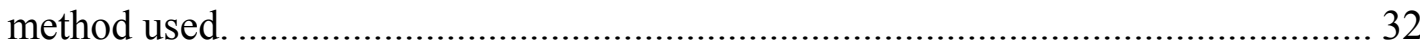

Fig. 2.4 Color score means for needle (N) and needle-free (NF) injected longissimus

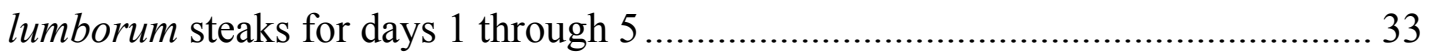

Fig. 2.5 Discoloration means for needle (N) and needle-free (NF) injected longissimus

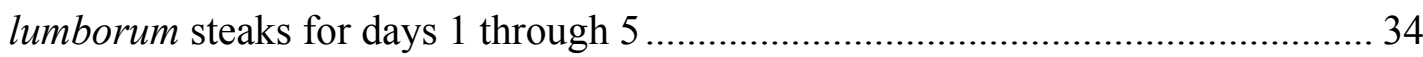

Fig. 2.6 Longissimus lumborum slice shear force means for needle (N) and needle-free

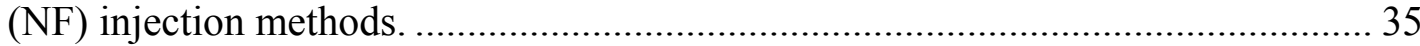

Fig. 2.7 Cooking loss of longissimus lumborum steaks for injection methods................ 37

Fig. 2.8 Trained sensory panel scores for longissimus lumborum steaks injected by either

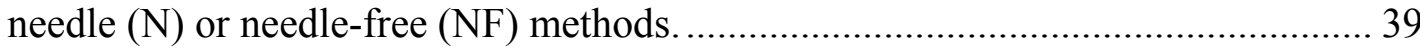

Fig. 2.9 Pump yield for longissimus lumborum steaks injected by needle $(\mathrm{N})$.............. 41

Fig. 2.10 Longissimus lumborum slice shear force means for steaks injected by needle

$(\mathrm{N})$ or needle-free (NF) methods with either a calcium lactate or phosphate solution.

Fig. 2.11 Cooking loss for longissimus lumborum steaks injected by needle $(\mathrm{N})$ or needlefree (NF) methods using either the calcium lactate or phosphate solution. 45

Fig. 2.12 Trained sensory panel scores for longissimus lumborum steaks injected by needle $(\mathrm{N})$ or needle-free $(\mathrm{NF})$ methods.

Fig. 2.13 Trained sensory panel scores for longissimus lumborum steaks injection enhanced with either the calcium lactate or phosphate solution. 


\section{Acknowledgements}

I now look back on the events of my life with a clearer understanding of God's purposes for taking me the direction that He chose. Graduate school was a part of that perfect plan, and that couldn't be more obvious after the multitude of answered prayers that I've seen over the past two years! With that stated, I first owe all the credit to God for His mercy; however, He used many people along the way to bless me beyond measure. Among that list are many whom I'm sure to mistakenly leave out, and others whom I never knew were a part of the plan. However, I'm thankful to all who were a part of my success, and I'll try to list a few of them.

Thanks Mom and Dad for all of your love and support, not only these last two years, but throughout my life. You have always put yourselves last and counted every success of mine as a success of your own. Your support of my dreams that have taken me so far from home is a testament to your selflessness. I have no doubt that you both sent many prayers up on my behalf, and each one was vital to my success. I want to thank my brother Brian for his life-long friendship and support through everything I've ever done. Karen, I wish I had the words to express my gratitude for the blessing that you are. I have a shoebox stuffed full of all the cards of encouragement that you've sent over the last two years. I know that each one represents about 1,000 prayers on my behalf. You know more about what's gone on in my life these last two years than I do. I guess it's time for the faculty to know that you are the one who reminded me to go to seminar every week! Haha! That's a product of your eagerness to listen and a reflection of your concern for me.

Without a doubt, I value my time assisting in coaching the livestock judging team more than anything else that I did throughout graduate school. If not for that opportunity, I would not have returned for another degree. I thank Dr. Scott Schaake for allowing me that experience. I also owe much thanks to all of my fellow graduate students. My project required help from many and couldn't have been done without you all! Luke, I think you were as loyal as anyone to help with possibly the world's worst job, needle-free 
injections. Haha! Rajarshi Dey, I can never thank you enough for all of your sincere friendship and help in statistics. Clearly, my committee deserves the utmost thanks for their time and patients. Dr. Hollis, you really went above the call of duty during the stress of my research to help with some unforeseen problems. I think it was just a testament to who you are. Thanks for everything! Finally, Dr. Dikeman, I would have never landed in meat science without your influence. Your influence on me goes back to my junior year when I took your Livestock and Meat Evaluation course. Though I had no idea what was in store, I learned that you give your best to all your students. That has held true! However, what I most appreciate about you is your character and all that you represent as a role model even beyond the walls of Weber Hall. I count myself blessed to have gotten to know you more closely these past two years and will take your life-lessons and friendship with me wherever I go! 


\section{Dedication}

I dedicate my thesis to my parents, Sammy and Cathy. Thanks Mom and Dad for making this opportunity possible! I know that the opportunity comes with no small cost to you both, and I am forever grateful for all your love and support. 


\section{CHAPTER 1 - Literature Review}

Tenderness, juiciness, and flavor contribute to the overall eating satisfaction and palatability of beef products. Some of these important characteristics have, for decades, been improved by such practices as injection enhancement and blade tenderization (Grobbel et al., 2008). In fact, many processing methods that positively impact the appearance and palatability of meat have been the focus of much research for years.

\section{Non-Intact Beef Products}

The Food Safety and Inspection Service (FSIS) describes beef products that are injection enhanced, reconstructed into formed entrees, or mechanically tenderized, as being non-intact. Also included in this category are beef products that have been processed by chopping, grinding, flaking or mincing (American Meat Institute, 2006).

It is important to make the distinction between beef products that are intact and those that are not because some research suggests that non-intact beef products have the potential for a $3-4 \%$ bacterial translocation from the surface to the interior of the meat (Sporing, 1999). If bacterial translocation occurs, beef needs to be cooked to an internal temperature of $71 \mathrm{C}$ to ensure food safety (USDA, 1997).

\section{Injection Enhancement of Meat}

A common practice in the meat industry is injection enhancement. It has been proven to improve many traits such as tenderness, juiciness, color stability, and cook yields (Grobbel et al., 2008; Knock et al., 2006b; Molina, 2005). Much research has been conducted to determine the effects of injection enhancement on meat as well as the optimal enhancement solution.

\section{Effects on Instrumental Tenderness and Sensory Traits}

Grobbel et al. (2008) reported results of sensory analysis of enhanced and nonenhanced beef products. In that study, paired longissimus lumborum, semitendinosus, and triceps brachii from USDA Select, A-maturity carcasses were utilized. On d 7 postmortem, each of three muscles from one side of the carcass was enhanced with a solution containing beef broth, potassium lactate, sodium phosphate, salt, and rosemary. 
The muscles from the opposite side of the carcass were not enhanced. Steaks were packaged and stored in different atmospheres until d 18 when they were removed from packages, vacuum packaged, and frozen at -20 C until later sensory analysis. Steaks were later thawed overnight $(2 \mathrm{C})$ and cooked to an internal temperature of $70 \mathrm{C}$. Although their study also looked at different packaging atmospheres and interactions between packaging treatments and enhancement, they reported main effects for enhancement and non-enhancement. They found that enhanced steaks from all muscles were juicier than non-enhanced steaks. Enhanced steaks from all three muscles had less perceptible connective tissue than non-enhanced steaks. All enhanced steaks had more off-flavors than non-enhanced steaks with typical descriptors of salty and metallic or chemical. They reported that panelists commented that enhanced steaks also had an undesirable mushy texture. Grobbel et al. (2008) reported that Warner-Bratzler shear force (WBSF) values indicated that enhanced steaks were more tender than non-enhanced steaks on each day postmortem that meat was evaluated $(7,14,18$, and 28$)$. In their study, $\mathrm{d} 7$ postmortem was the day of injection enhancement, so lower WBSF values on $\mathrm{d} 7$ indicated an immediate tenderizing effect as a result of enhancement. They believe that injection-enhancement might improve tenderness through a dilution effect or through physically altering the muscle structure with the needles used to inject the solution; however, they admitted that the exact method of action is unknown.

A study by Molina (2005) evaluated enhancement in 8 different beef chuck muscles using a solution containing $5.0 \%$ salt, and $4.0 \%$ sodium tripolyphosphate with a $10 \%$ pump yield on four different treatments: control, marinated, needle-pumped, and vacuum-tumbled. Some of these muscles were cooked on a grill, and the rest were oven roasted. All of them were cooked to an internal temperature of $71^{\circ} \mathrm{C}$. Sensory evaluations and WBSF determinations were conducted immediately after cooking. They found that 4 out of 8 needle-pumped muscles had improved tenderness. Brine treatment reduced sensory detected connective tissue in only 2 of the 8 muscles. More off-flavors were detected by the panel for marinated samples from 6 of the 8 muscles. The needlepumped treatment reduced WBSF values compared to the control in 3 out of 8 muscles. Regardless of the application method, palatability traits were generally enhanced by brine treatments. 
A study by Hoffman et al. (2008) evaluated the effects of injection enhancement with salt and phosphate on 4 different beef muscles. They reported that panelists rated enhanced samples juicier and more tender than non-enhanced samples. However, panelists rated enhanced steaks saltier and with less overall beef flavor than non-enhanced steaks.

An earlier study by Hoffman (2006) compared enhanced to non-enhanced beef semitendinosus and longissimus muscles from both sides of the carcasses of 10 mature Simmental cows ranging from 10 to $13 \mathrm{yrs}$ old. At 7 postmortem, one side was injected with a commercial salt mixture containing sodium and potassium di- and triphosphates, lactate and sodium chloride at a pumped yield of $15 \%$; the other side served as a control. Muscles were then aged for an additional $7 \mathrm{~d}$. Injection reduced WBSF from about 50-N in control samples to 37-N for longissimus samples and 42-N for semitendinosus samples. Sensory analysis revealed that juiciness and tenderness were perceived to be higher in injected samples. Beef flavor intensity was lower for injected samples, and panelists detected more salty off-flavors in injected steaks. Although the sample size in this study needed to be larger, their results pointed to increased tenderness and juiciness with more off-flavor intensity and less beef flavor associated with enhanced steaks. These results generally match those of other similar research.

Lennon et al. (2006) explored injection enhancement of two different beef muscles that were injected whole, injected and reformed, or injected with flavor added and reformed. They used a salt/phosphate solution at a 15\% pump yield. In their results, all injection treatments reduced WBSF values over controls, and sensory tenderness ratings were also higher for injected samples versus non-injected controls. In their study, beef flavor intensity was actually higher in the injected whole muscles than it was in either the control or the injected and reformed product. Other literature suggests that improving beef flavor intensity with injection enhancement is uncommon. This rare occurrence is even more unusual given that Lennon et al. (2006) used a salt/phosphate solution, which is even more uncommonly associated with having a positive impact on flavor.

A study by McGee et al. (2003) revealed that beef inside rounds injected with a sodium lactate, sodium tripolyphosphate, and sodium chloride solution were more tender than non-enhanced controls according to both WBSF values and sensory ratings. 


\section{Effects on pH and Color}

In the study by Grobbel et al. (2008), enhanced steaks were darker initially than non-enhanced steaks. They believe this might have been a result of the lactate that was used in their brine. They also reported that $\mathrm{pH}$ was higher in enhanced steaks from all muscles than non-enhanced steaks. This was believed to be a result of the phosphate and/or lactate in the enhancement solution.

Hoffman (2006) compared muscles injected with a commercial salt mixture to non-enhanced muscles and found that injection significantly increased meat $\mathrm{pH}$ by 0.3 units in longissimus samples. They reported that injected samples were pinker during storage and after cooking.

Wheeler et al. (1996) conducted research in which bottom round cuts were injected with calcium chloride to determine its effect on meat color. They found that enhanced steaks were darker, and had more metmyoglobin formation on $\mathrm{d} 5$ and $\mathrm{d} 7$ than nonenhanced steaks.

Lennon et al. (2006) reported that when trained panelists were asked to rate the color of injection-enhanced beef muscles on an acceptability scale of 1 (worst) to 6 (best), they detected no difference between the injection-enhanced samples and the non-enhanced controls.

Increases in $\mathrm{pH}$ after injection enhancement can be expected, but there are some inconsistencies with regard to its effects on meat color. The ingredients present in the enhancing solution may impact the effects of enhancement on $\mathrm{pH}$ and/or meat color.

\section{Effects on Cooking Loss}

Grobbel et al. (2008) reported that enhanced steaks $(19.9 \% \pm 0.4)$ had less cooking loss than non-enhanced steaks $(26.3 \% \pm 0.4)$.

In the study by Molina et al. (2005), the addition of salt and STPP increased water-holding capacity resulting in less weight loss due to cooking in 7 of the 8 muscles that were enhanced and oven-roasted relative to the untreated control. These authors reported that the mean cooking loss for enhanced oven-roasted muscles was $21 \%$ as compared to $31 \%$ for the untreated, oven-roasted control muscles. They found that the 
average cooking loss for enhanced grilled muscles was $24 \%$ in contrast to the grilled control muscles, which was almost $30 \%$.

Lennon et al. (2006) conducted a study in which beef Supraspinatus and Triceps brachii muscles were subjected to one of three treatments that all utilized a salt/phosphate solution at a 15\% pump yield. Treatments were as follows: 1) injected whole, 2) injected and reformed, or 3) injected with flavor added and reformed. All treatments were compared to controls that were non-injected whole muscles. The triceps brachii muscles that were injected with flavor added and reformed had higher cooking losses than controls, but all other treatments were not different from controls.

McGee et al. (2003) injected paired inside round beef muscles from 30 USDA Select grade carcasses with a solution of sodium lactate, sodium tripolyphosphate, and sodium chloride. They reported that injected samples had lower percentages of cooking and reheating losses than non-enhanced controls.

\section{Ingredients}

A study by Knock et al. (2006a) evaluated the effects of potassium lactate, sodium chloride, and sodium acetate on injection-enhanced beef strip-loin steaks. Steaks were packaged in a high-oxygen modified atmosphere and evaluated on d 2, 9, and 14 by sensory panelists. Steaks enhanced with potassium lactate had the highest brown-roasted and beef flavors with limited rancid flavors as compared to the other treatments. Sodium chloride increased salty and rancid flavors. Other sensory traits were not different among treatments.

Knock et al. (2006b) looked at injection enhancement of beef rib steaks with different combinations of potassium lactate, sodium chloride, sodium tripolyphosphate, and sodium acetate. They concluded that potassium lactate was best at improving color stability.

Potassium lactate is shown throughout the literature to improve flavors and color stability while reducing off-flavors.

Mancini et al. (2008) evaluated the effects of lactate enhancement on strip-loins and tenderloins. They compared steaks injected with a solution containing either $12.5 \%$ or 
$25 \%$ lactate to non-injected controls and water-injected controls. Steaks were packaged in different atmospheres. Lactate, at the higher concentration, resulted in darker steaks in all atmospheres; however, lactate injection-enhancement at the higher concentration improved redness in those steaks packaged in high oxygen. Mancini et al. (2008) reported that lactate had no effect on discoloration.

Lawrence et al. (2003) compared calcium ascorbate, calcium chloride, and calcium lactate to determine which was best, from a meat quality and safety standpoint, as enhancing solutions for beef strip loins. They found no difference in WBSF values or sensory panel tenderness among treatments. However, the calcium ascorbate and calcium chloride treatments resulted in less beef flavor and more off-flavors than the calcium lactate treatment. Aerobic microbial plate counts were lowest for the calcium lactate treatment. They recommend using calcium lactate to enhance meat quality.

Lawrence et al. (2004) conducted a study with injection enhancement comparing the use of a solution of phosphate and salt plus rosemary to a solution of calcium lactate plus rosemary. They did not find differences in WBSF values between treatments, but panelists perceived steaks enhanced with calcium lactate plus rosemary to be less tender and juicy than steaks enhanced with phosphate and salt plus rosemary. However, there was a higher occurrence of metallic and salty off-flavors, a darker initial color, and more color deterioration in steaks that were enhanced with the phosphate and salt plus rosemary solution.

Apart from the work of Lawrence et al. (2003, 2004), there is still limited literature available comparing calcium salts. Available literature is equally limited for the comparison of a calcium lactate solution to a phosphate/salt solution for enhancement of beef. However, based on the work of Lawrence et al. $(2003,2004)$, while their phosphate plus salt solution had the advantage of tenderness, juiciness, and yields, it came at the expense of appearance and flavor.

Baublits et al. (2006) evaluated different types of phosphates, differing concentrations of phosphates, and different levels of pump yields for effectiveness at improving water retention, cooked yields and palatability of beef biceps femoris muscles. They compared sodium hexametaphosphate (SHMP), sodium tripolyphosphate (STPP), and tetrasodium pyrophosphate (TSPP) at concentrations of either $2.0 \%$ or $4.0 \%$ of the 
solution. Muscles were injected at a level of either $12 \%$ pump or $18 \%$ pump. In their study, STPP and TSPP were both effective at raising the $\mathrm{pH}$ over that of SHMP enhanced or untreated muscles. Phosphate concentrations of only $2 \%$ of the solution resulted in even higher cooking losses than non-enhanced meat, but phosphate enhancement at a concentration of $4 \%$ of the solution yielded similar cooking losses as controls. Steaks enhanced at an 18\% pump had greater cooking losses than non-enhanced steaks, whereas steaks enhanced at a $12 \%$ pump had cooking losses similar to non-enhanced steaks. Enhancement with any of the three phosphate types or either concentration did not improve sensory tenderness or juiciness characteristics compared to non-enhanced muscles. However, enhancement at an $18 \%$ pump rate allowed for greater overall tenderness sensory scores compared to the $12 \%$ pump rate. They concluded that the higher phosphate concentrations, and STPP and TSPP could all be utilized to obtain cooked yields similar to untreated samples and that phosphate enhancement without the addition of sodium chloride generally did not improve water retention, cooked yields and palatability compared to untreated samples. Although results of Baublits et al. (2006) did not show many differences, the study demonstrates that phosphate is not effective at improving sensory traits or yields when used without the addition of salt. I conclude, based on their results, that SHMP is not the best phosphate choice for raising $\mathrm{pH}$ and thus could not be expected to be as effective at water binding as STPP or TSPP when used in conjunction with salt. I also conclude that a phosphate concentration of $4 \%$ of the solution is more appropriate than lower concentrations when trying to minimize cooking losses. I question the objective of their comparison of pump yields because a pump yield of $18 \%$ would likely never be accepted in industry and, therefore, has no practical application.

An earlier study by Baublits et al. (2005) reinforces the concept that, neither salt nor phosphate is independently as beneficial as they are in combination with each other. In this study, a solution containing $2.0 \%$ sodium chloride and either SHMP, STPP, or TSPP at concentrations of $2.0 \%$ or $4.0 \%$ of solution was injected into beef biceps femoris muscles. Injections were made at either $12 \%$ or $18 \%$ pump yields. Muscles treated with all three types of phosphates had decreased free water compared to untreated muscles. Muscles treated with TSPP bound greater additional water than untreated muscles while muscles treated with the other phosphate types did not differ from controls with regard to 
water binding. Regardless of phosphate type, the higher concentrations of phosphate inclusion resulted in greater water binding. They determined that, while steaks treated with SHMP did not differ from controls, those steaks treated with both STPP and TSPP had less cooking loss than non-enhanced steaks. There were no difference in free water, water binding, or cooking losses between those steaks injected with 18\% pump and those injected with the $12 \%$ pump yield. Trained panelists rated all enhanced steaks with greater tenderness and juiciness as compared with non-enhanced steaks. Tenderness and juiciness scores also were superior among those steaks treated with both salt and phosphate as compared with those injected with salt alone. The higher phosphate concentration and higher pump yield resulted in greater sensory tenderness than did the lower phosphate concentration and lower pump yield. In summary of their study, STPP and TSPP both improved water retention, cooked yield, and palatability. Enhancement with a phosphate plus salt solution at an $18 \%$ pump rate, compared to a $12 \%$ pump rate, improved sensory tenderness without decreasing product yields; however, this has little practical value because the $18 \%$ pump rate will not likely be adopted by industry or accepted by consumers. I conclude that TSPP was the best phosphate type for improving water binding while SHMP was the worst phosphate type when trying to improve cook yields. Again, the higher phosphate concentration of $4.0 \%$ of solution was more beneficial at water binding, and it also resulted in greater tenderness. Salt and phosphate need to be used in combination for maximum tenderness and juiciness.

Myoglobin and lipid oxidation can be reduced in enhanced products with the addition of rosemary extract as was demonstrated in a study by Balentine et al. (2005) that evaluated the usefulness of rosemary extract as an antioxidant in ground beef. In experiment 1 , rosemary was added at four different stages of the grinding process in ground beef (trim, cube, coarse, and fine ground respectively). The beef was evaluated for color and thiobarbituric acid reactive substances (TBARS) values during $144 \mathrm{~h}$ of storage at $4 \mathrm{C}$. Results showed that when rosemary was added to the pre-grinding treatments of trim and cube, ground beef had the highest $a^{*}$ values (redness), oxymyoglobin content, and lowest TBARS values after $144 \mathrm{~h}$ of storage. In experiment 2 , rosemary was added to case ready ground beef, and case ready ground beef without rosemary served as a control. Part of both the rosemary treated and untreated ground beef was inoculated with a level of 
$10^{7} \mathrm{CFU} / \mathrm{g}$ Escherichia coli and the other part was not. Microbial counts, color, and TBARS values were measured during $144 \mathrm{~h}$ of simulated storage. Results showed that both the rosemary treated samples that were inoculated and not inoculated remained redder longer and had lower TBARS values than the untreated inoculated and non inoculated controls. There was no significant inhibition of $E$. coli by the rosemary extract.

Different ingredients have been investigated for use in enhancement solutions. Potassium lactate has been shown to improve brown roasted and beef flavors, limit rancid flavors, and cause darker initial meat color, yet improve color stability. Calcium lactate solutions have resulted in more beef flavor and microbial inhibition with fewer off-flavors than solutions with other calcium salts. TSPP may be the best phosphate type for improving water binding while SHMP is the worst source of phosphate for improving water binding and cooked yields. A phosphate concentration of $4 \%$ should offer the advantages of water binding and tenderness versus lower concentrations. Salt and phosphate need to be used in combination for maximum tenderness, juiciness and water binding. Rosemary can help reduce both myoglobin and lipid oxidation and thus keep meat redder longer. Finally, while solutions of a phosphate plus salt base have the advantage of tenderness, juiciness and yields, they come at the expense of appearance and flavor of meat versus solutions with a calcium lactate base.

\section{Mechanical Tenderization}

Once consumers have purchased a beef product, most of them judge its quality and overall acceptability based on tenderness (Boleman et al., 1997; Neely et al., 1998). As a result, much research has been conducted to find mechanical methods of improving meat tenderness for consumers. Needling, cubing, and pounding are all forms of mechanical tenderization (American Meat Institute, 2006).

George-Evins et al. (2004) investigated the effects of USDA quality grade classification, aging period, blade tenderization passes, and endpoint cooking temperature on tenderness. They used top sirloin butts from Select, Choice, and Certified Angus Beef carcasses and aged them for 7, 14, or $21 \mathrm{~d}$. Muscles were either not tenderized at all, blade tenderized once, or blade tenderized twice. Three steaks from each muscle section were randomly selected and assigned to one of three endpoint cooking temperatures. To 
no surprise, with each increase in aging period came lower WBSF values. Panelists seemed to concur with this effect. They rated samples with less connective tissue and more overall tenderness as aging time increased. Additionally, steaks blade tenderized twice had lower WBSF values than steaks blade tenderized once or not at all. Steaks blade tenderized one or two times received higher sensory scores for myofibrillar and overall tenderness than steaks not blade tenderized. Within each quality grade classification, WBSF values would suggest that increasing cooking temperatures resulted in increased toughness. When cooked to the two higher temperatures, Choice and Certified Angus Beef steaks had lower WBSF values than Select steaks. This suggests that higher marbling might be particularly beneficial for those consumers who cook steaks to medium-well or higher degrees of doneness.

Pietrasik and Shand (2003) explored blade tenderization and tumbling of beef roasts. In their study, some roasts were blade tenderized and injection enhanced while the remaining roasts were tumbled. The roasts that they designated to be blade tenderized were tenderized with one pass through the machine and then injected with brine formulated to result in a final product with $1.8 \%$ salt and $0.3 \%$ STPP. Roasts designated for tumbling were vacuum packaged and intermittently tumbled (20 min on, $10 \mathrm{~min}$ off) for 0,2 or $16 \mathrm{~h}$. Roasts from all treatments were then placed in cooking bags and cooked in a water bath to an internal temperature of $72 \mathrm{C}$. WBSF values and a texture profile analysis were obtained for muscles from all treatments. Extended tumbling time $(16 \mathrm{~h})$ decreased shear force and hardness values by $50-60 \%$ over those roasts that were not treated at all. Blade tenderization and injection enhancement decreased WBSF values 15$20 \%$ more than tumbling for $2 \mathrm{~h}$ did, but tumbling for $16 \mathrm{~h}$ was just as effective at improving tenderness as the blade tenderization plus injection enhancement treatment was.

According to Bowker et al. (2007), hydrodynamic processing (HDP) is a method currently being researched as a means of mechanically tenderizing meat. It involves submerging packaged meat products in water and exposing them to a high pressure shock wave. This shockwave was generated using a small amount of explosives, but alternative technologies are being investigated. HDP treated samples appear normal and trained sensory panelists detect no difference in flavor or visual assessment, but they score HDP treated samples significantly more tender than untreated controls. 
Different factors such as age, maturity, gender, USDA quality grade, marbling, breed and muscle characteristics can affect tenderness of meat from beef cattle. Brahman cattle are known for tougher meat as compared to other purebred cattle. For that reason, Liu et al. (2006) chose carcasses from Brahman cattle selected for toughness to determine the tenderization effects of HDP, blade tenderization (BT) and a combination of BT followed by HDP (BT+HDP). WBSF testing was performed on the day of treatment and after 7 days of storage. Initially, BT treated steaks and HDP treated steaks had an 18\% improvement in tenderness versus control steaks. Oddly, BT+HDP treated steaks had only a $14 \%$ improvement in initial tenderness versus controls. On $\mathrm{d} 7$, tenderness had increased for both the HDP and BT+HDP treated steaks, but tenderness did not change between $\mathrm{d} 0$ and $\mathrm{d} 7$ for the BT treatment group. Aging alone caused a 20\% increase in tenderness among control samples. Overall, tenderness improvements for the BT+HDP and HDP treated samples on $\mathrm{d} 7$ versus controls on $\mathrm{d} 0$ were $37 \%$ and $29 \%$, respectively. Although BT alone caused instant tenderization, because there was no improvement in tenderness with aging time, the control steaks were actually more tender on $\mathrm{d} 7$ than the BT treated steaks. HDP and BT+HDP provided instant tenderization and, although steaks treated with BT alone did not improve in tenderness over time, when BT was used in combination with HDP, aging improved tenderness. HDP treated steaks also had improved tenderness with additional aging time. They found that steaks treated with the combination treatment had the greatest amount of overall improvement in tenderness by the end of the $7 \mathrm{~d}$ aging period ( $37 \%$ versus $20 \%$ for controls).

A study by Loucks et al. (1984) examined the effects of mechanical tenderization (MT) on tenderness, cooking time, and cooking losses on both pre-rigor and post-rigor beef semimembranosus muscles. WBSF testing and trained sensory panel evaluations were conducted. Mechanically tenderizing pre-rigor roasts did not improve tenderness but it did for post-rigor roasts. Mechanically tenderized post-rigor roasts required more cooking time than the control, non-tenderized, post-rigor roasts from paired sides. Postrigor roasts had more cooking losses as compared to pre-rigor roasts, but MT had no effect on cooking losses. According to panelists, even post-rigor roasts that were not MT still had superior tenderness to pre-rigor roasts that were MT. Loucks et al. (1984) also reported that panelists gave post-rigor roasts that had been MT the highest tenderness 
scores. Panelists' scores indicated that connective tissue amounts were lower when MT was utilized. In summary, pre-rigor roasts were tougher and less responsive to MT but had less cooking loss, which was only affected by the roasts' state of rigor mortis, not MT. The most tender roasts were post-rigor and MT.

Bowker et al. (2007) conducted a study where blade tenderization (BT), HDP, and BT followed by HDP (BT+HDP) were all examined for their effects on collagen solubility and muscle fiber characteristics of top rounds from Brahman cattle. Top rounds were divided into halves and randomly assigned to HDP, BT, or BT+HDP with each treatment sample having a paired control. HDP and BT+HDP increased collagen solubility, but the correlation between collagen solubility and tenderness in their study was low $(r=-0.41)$. All treatments increased fragmentation of myofibrils 35\% compared to controls. Bowker et al. (2007) concluded that BT physically disrupts the muscle structure to improve tenderness; whereas, HDP tenderization potentially results from both physical disruption of the muscle structure and some form of alteration to muscle proteins.

BT, HDP and BT+HDP all have immediate effects on tenderness. Tumbling for an extended time can be just as effective at improving tenderness as BT. HDP and HDP+BT treated steaks are both responsive to aging whereas steaks treat by BT alone do not respond to aging. $\mathrm{HDP}+\mathrm{BT}$ is the most effective method of improving tenderness. BT increases tenderness by physical disruption of muscle structure, whereas HDP increases tenderness by both physical disruption of muscle structure and alteration to muscle proteins.

Many reports have shown that MT significantly improves the tenderness of less tender cuts of meat and is one of the most effective and efficient methods used to ensure tenderness (Binder et al., 1985; Flores et al., 1986; Loucks et al., 1984; Lyon et al., 1983; Mandigo and Olson, 1982; Savell et al., 1977; Tatum et al., 1978). 


\section{Vaccinating Livestock with a Needle-Free Injector}

Needle-free injection technology has already been researched in the livestock industry and is being investigated further. Houser et al. (2004) suggested that the use of a needle-free injector would eliminate the risk of carcass damage that would occur from needle fragments left behind after needle injection. They used a needle-free injection device to vaccinate 130 pigs for pseudorabies and Mycoplasma hyopneumoniae. Pigs were divided into three treatment treatments: an unvaccinated control, vaccinated with the traditional hypodermic needle, or vaccinated with the needle-free air-powered device. Both injection methods produced similar serological responses that were significantly greater than those seen in unvaccinated controls. Injection method made no difference in the occurrence of lesions at the injection sites, and carcass defects did not occur with either injection method used.

Hollis et al. (2005) conducted research to determine the effectiveness of a needlefree injection device at delivering vaccine to cattle. They vaccinated yearling feedlot steers with 5-way modified-live virus vaccine and Mannheimia haemolytica (MH) bacterin-toxoid utilizing either the needle-free injection system or the traditional hypodermic needle injection technique. They collected blood samples from all steers at the time of vaccination and $21 \mathrm{~d}$ later. Serum was analyzed for antibody titers to the infectious bovine rhinotracheitis (IBR) virus and MH leukotoxin. The serological response to the IBR portion of the 5-way vaccine was higher among the needle-free injected cattle than the needle injected cattle at $21 \mathrm{~d}$ post-injection. The $\mathrm{MH}$ vaccine was no different between treatments with regard to antibody response.

Mousel et al. (2008) stated, "Repeatedly using one needle to vaccinate livestock can laterally transmit diseases. A pneumatic, needle-free injector eliminates needles and thus the concern of lateral transmission." Mousel et al. (2008) conducted a study comparing injection time and antibody response of vaccines administered with either a needle-free injector or traditional needle injections on eight-month-old wethers. Sheep were given primary and secondary inoculations of ovalbumin. Serum samples were collected before and after inoculations on d $0,14,28$, and 42 . Inoculation of 100 wethers 
with the needle-free injector required $60 \%$ less time than needle injections when a new needle was used on every animal. Antibody titers were the same for those wethers inoculated with the needle-fee injector as they were for those wethers inoculated with needle injections on $\mathrm{d} 14,28$, and 42 . As expected, titers increased from primary and secondary vaccinations for both treatment groups. They concluded that a needle-free injector can be used to elicit the same antibody response in sheep as needle injections while saving time. They recommend the needle-free injector as a means of reducing lateral transmission of blood-borne diseases, eliminating biohazard waste (e.g., used needles), eliminating the incidence of needle fragments being broken off in muscle, and preventing accidental needle sticks for livestock handlers when vaccinating sheep. Considering the potential problems with needle injection of livestock, it is not surprising that research has been conducted to explore an alternative to needle injections.

\section{Summary}

Beef products that are mechanically tenderized, restructured, or injection-enhanced are all considered non-intact. Additional food safety measures need to be taken with these non-intact products. In general, enhanced beef has been found to be juicier and more tender with less perceptible connective tissue than non-enhanced beef. Although there are inconsistencies, most studies have shown more off-flavors, less beef flavor intensity, and unusual textures associated with injection-enhanced products. Injection enhancement tends to raise the $\mathrm{pH}$ and darken the color of meat while increasing color stability. Enhanced meat tends to have greater water-binding ability and thus less cook loss than non-enhanced meat. Different ingredients are used in enhancing solutions such as salt, phosphates, and lactates. Salt and phosphate seem to be more effective at improving cooking yields and palatability when used in combination with each other rather than independently. Potassium lactate has been shown to be beneficial at improving brownroasted and beef flavors while improving color stability. Calcium lactate has proven itself as the best choice of calcium salts from the standpoint of its effects on microbial plate counts, beef flavor intensity, and off-flavors. Solutions of salt and phosphate were found more effective at improving tenderness than calcium lactate solutions but generally resulted in less beef flavor and more off-flavors. Sodium tripolyphosphate (STPP) and 
tetrasodium pyrophosphate (TSPP) were superior to sodium hexametaphosphate (SHMP) at reducing cooking loss. Increases in phosphate concentration have generally resulted in increased tenderness. Rosemary has been proven beneficial at reducing both myoglobin and lipid oxidation thus keeping meat redder for a longer period of time.

While there are different methods of mechanical tenderization, they all most commonly result in decreased WBSF values and higher perceived tenderness. It is believed that while some methods of mechanical tenderization improve tenderness by physically disrupting the muscle structure, others may also improve tenderness by some form of alteration to muscle proteins.

The use of needle-free technology has been proven just as effective at delivering vaccines to animals as the traditional hypodermic needle injection method. Needle-free injection devices have been suggested to save time, reduce the risk of lateral transmission of diseases, eliminate biohazard waste, and prevent accidental needle sticks of livestock handlers. Needle-free technology has begun to be researched to determine its effects on injection site lesions of livestock, and it clearly offers the advantage of eliminating needle fragments in carcasses.

Needle-free technology seems to offer many advantages to the livestock industry. It seems logical that it could be a vital replacement for needle injections in other applications too. If the meat industry found needle-free technology effective at delivering solutions into meat, it could be used as an alternative to needle injection enhancement and should offer advantages, especially for bone-in products. Therefore, I chose to research the potential advantages of needle-free injection enhancement of meat. 


\section{Literature Cited}

American Meat Institue, National Cattlemen's Beef Association, National Meat Association, and Southwest Meat Association. 2006. Best Practices: Pathogen control during tenderization/enhancing of whole muscle cuts.

Balentine, C. W., P. G. Crandall, C. A. O’Bryan, D. Q. Duong, and F. W. Pohlman. 2006. The pre- and post-grinding application of rosemary and its effects on lipid oxidation and color during storage of ground beef. Meat Sci. 73:413-421.

Baublits, R. T., F. W. Pohlman, A. H. Brown, Jr., and Z. B. Johnson. 2005. Effects of sodium chloride, phosphate type and concentration, and pump rate on beef biceps femoris quality and sensory characteristics. Meat Sci. 70:205-214.

Baublits, R. T., F. W. Pohlman, A. H. Brown, Jr., and Z. B. Johnson. 2006. Enhancement with varying phosphate types, concentrations, and pump rates, without sodium chloride on beef biceps femoris quality and sensory characteristics. Meat Sci. $72: 404-414$.

Binder, T. D., R. E. Montgomery, C. P. Bagley and K. W. McMillin. 1985. Influence of electrical stimulation, blade tenderization and postmortem vacuum aging upon the acceptability of beef finished on forage or grain. J. Anim. Sci. 61:584-589.

Boleman, S. J., S. L. Boleman, R. K. Miller, J. F. Taylor, H. R. Cross, T. L. Wheeler, M. Koohmaraie, S. D. Shackelford, M. F. Miller, and R. L. West. 1997. Consumer evaluation of beef of known categories of tenderness. J. Anim. Sci. 75:15211524.

Bowker, B. C., M. Liu, M. B. Solomon, J. S. Eastridge, T. Fahrenholz, and B. T. Vinyard. 2007. Effects of hydrodynamic pressure processing and blade tenderization on intramuscular collagen and tenderness-related protein characteristics of top rounds from Brahman cattle. J. of Muscle Foods 18:35-55.

Dikeman, M. E. 1987. Fat reduction in animals and the effects on palatability and consumer acceptance of meat products. Proc. Meat Conf. 40:93. 
Flores, H. A., C. L. Kastner, D. H. Kropf and M. C. Hunt. 1986. Effects of blade tenderization and trimming of connective tissue on hot-boned, restructured, pre-cooked roasts from cows. J. Food Sci. 51:1176-1179.

George-Evins, C. D., J. A. Unruh, A. T. Waylan, and J. L. Marsden. 2004. Influence of quality classification, aging period, blade tenderization, and endpoint cooking temperature on cooking characteristics and tenderness of beef gluteus meduis steaks. J. Anim. Sci. 82:1863-1867.

Grobbel, J. P., M. E. Dikeman, M. C. Hunt, and G. A. Milliken. 2008. Effects of different packaging atmospheres and injection-enhancement on beef tenderness, sensory attributes, desmin degradation, and display color. J. Anim. Sci. 86:2697-2710.

Hoffman, L. C. 2006. Sensory and physical characteristics of enhanced vs. nonenhanced meat from mature cows. Meat Sci. 72:195-202.

Hoffman, L. C., M. Muller, and A. Vermaak. 2008. Sensory and preference testing of selected beef muscles infused with a phosphate and lactate blend. Meat Sci. 80:10551060.

Hollis, L. C., J. F. Smith, B. J. Johnson, S. Kapil, D. A. Mosier. 2005. A comparison of serological responses when modified-live infectious bovine rhinotracheitis virus vaccine and Mannheimia haemolytica bacterin-toxoid are administered with needlefree versus conventional needle-based injection in yearling feedlot steers. Bov. Practitioner 39:106-109.

Houser, T. A., J. G. Sebranek, B. J. Thacker, T. J. Baas, D. Nilubol, E. L. Thacker, F. Kruse. 2004. Effectiveness of transdermal, needle-free injections for reducing pork carcass defects. Meat Sci. 68:329-332.

Knock, R. C., M. Seyfert, M. C. Hunt, M. E. Dikeman, R. A. Mancini, J. A. Unruh, J. J. Higgins, and R. A. Monderen. 2006a. Effects of potassium lactate, sodium chloride, and sodium acetate on surface shininess/gloss and sensory properties of injection-enhanced beef strip-loin steaks. Meat Sci. 74:319-326.

Knock, R. C., M. Seyfert, M. C. Hunt, M. E. Dikeman, R. A. Mancini, J. A. Unruh, J. J. Higgins, and R. A. Monderen. 2006b. Effects of potassium lactate, sodium chloride, sodium tripolyphosphate, and sodium acetate on colour, colour stability, and oxidative properties of injection-ehanced beef rib steaks. Meat Sci. 74:312-318. 
Lawrence, T. E., M. E. Dikeman, M. C. Hunt, C. L. Kastner, and D. E. Johnson. 2003. Effects of calcium salts on beef longissimus quality. Meat Sci. 64(2):299-308.

Lawrence, T. E., M. E. Dikeman, M. C. Hunt, C. L. Kastner, and D. E. Johnson. 2004. Effects of enhancing beef longissimus with phosphate plus salt, or calcium lactate plus non-phosphate water binders plus rosemary extract. Meat Sci. 67: 129-137.

Lennon, A. M., S. S. Moon, P. Ward, E. E. O’Neill, and T. Kenny. 2006. Effects of enhancement procedures on whole and re-formed beef forequarter muscles. Meat Sci. 72:513-517.

Liu, M., M. B. Solomon, B. T. Vinyard, J. A. Callahan, J. R. Patel, R. West, C. C. Chase. 2006. Use of hydrodynamic pressure processing and blade tenderization to tenderize top rounds from Brahman cattle. Journal of Muscle Foods. 17:79-91.

Loucks, L. J., E. E. Ray, B. W. Berry, E. A. Leighton, and D. G. Bray. 1984. Effects of mechanical tenderization and cooking treatments upon product attributes of preand post-rigor beef roasts. J. Anim. Sci. 58:626-630.

Lyon, M., C. L. Kastner, M. E. Dikeman, M. C. Hunt, D. H. Kropf, and J. R. Schwenke. 1983. Effects of electrical stimulation, aging, and blade tenderization on hotboned beef Psoas major and Triceps brachii muscles. J. Food Sci. 48:131-135.

Mancini, R. A., S. P. Suman, M. K. R. Konda, and R. Ramanathan. 2009. Effect of carbon monoxide packaging and lactate enhancement on the color stability of beef steaks stored at 1 C for 9 days. Meat Sci. 81:71-76.

Mandigo, R. W., and D. G. Olson. 1982. Effect of blade size for mechanically tenderizing beef rounds. J. Food Sci. 47:2095-2096.

McGee, M. R., K. L. Henry, J. C. Brooks, F. K. Ray, and J. B. Morgan. 2003. Injection of sodium chloride, sodium tripolyphosphate, and sodium lactate improves Warner-Bratzler shear and sensory characteristics of pre-cooked inside round roasts. Meat Sci. 64:273-277.

Miller, M. F., K. L. Huffman, S. Y. Gilbert, L. L. Hammon, and C. B. Ramsey. 1995. Retail consumer acceptance of beef tenderized with calcium chloride. J. Anim. Sci. 73:2308.

Molina, M. E., D. D. Johnson, R. L. West, and B. L. Gwartney. 2005. Enhancing palatability traits in beef chuck muscles. Meat Sci. 71: 52-61. 
Mousel, M. R., T. D. Leeds, S. N. White, L. M. Hoesing. 2008. Comparison of traditional needle vaccination to pneumatic, needle-free vaccination in sheep. J. Anim. Sci. 86:1468-1471.

Neely, T. R., C. L. Lorenzen, R. K. Miller, J. D. Tatum, J. W. Wise, J. F. Taylor, M. J. Buyck, J. O. Reagan and J. W. Savell. 1998. Beef customer satisfaction: role of cut, USDA quality, and city on in-home consumer ratings, J. Anim. Sci. 76:1027-1033.

Phebus, R. K., H. Thippareddi, S. Sporing, J. L. Marsden, and C. L. Kastner. 2000. Escherichia coli O157:H7 risk assessment for blade-tenderized steaks. In: Cattlemen's Day Report, Manhattan, KS.

Pietrasik, Z., and P. J. Shand. 2003. Effects of blade tenderization and tumbling time on the processing characteristics and tenderness of injected cooked roast beef. Meat Sci. 66:871-879.

Savell, J. W., F. K. McKeith, C. E. Murphey, G. C. Smith, and Z. L. Carpenter. 1982. Singular and combined effects of electrical stimulation, post-mortem ageing and blade tenderization on the palatability attributes of beef from young bulls. Meat Sci. 6:97109.

Seyfert, M., M. C. Hunt, R. A. Mancini, K. A. Hachmeister, D. H. Kropf, J. A. Unruh, and T. M. Loughin. 2005. Beef quadriceps hot boning and modified atmosphere packaging influence properties of injection-enhanced beef round muscles. J. Anim. Sci. 83:686-693.

Sporing, S. B. 1999. E. coli 0157:H7 risk assessment for production and cooking of blade tenderized beef steaks. Master Thesis. Kansas State University, Manhattan, KS.

Sundberg, P. (2000). Detectability of needle fragments in pork under packing plant conditions. In Proceedings of the American Association of Veterinary Practitioners Preconference Workshops (pp. 317-320).

Sutterfield, A. N. 2008. Microbial translocation of needle-free injection enhanced beef strip loins as compared with traditional needle injection. Master Thesis. Kansas State University, Manhattan, KS.

Tatum, J. D., G. C. Smith, and Z. L. Carpenter. 1978. Blade tenderization of steer, cow and bull beef. J. Food Sci. 43:819-822. 
USDA. 1997. USDA advises consumers to use a meat thermometer when cooking hamburger. FSIS News and Information Bulletin. FSIS. USDA. Washington DC

Wheeler, T. L., M. Koohmaraie, and S. D. Shackelford. 1996. Effect of vitamin C concentration and co-injection with calcium chloride on beef retail display color. J. Anim. Sci. 74:1846-1853. 


\section{CHAPTER 2 - A Comparison of Needle-Free and Needle Injection Methods and Solutions for Enhancement of Beef Longissimus Lumborum Muscles}

\section{Introduction}

Tenderness is the most important palatability attribute affecting consumers' overall eating experience (Dikeman, 1987; Miller et al., 1995). As a result, injection enhancement and blade tenderization have long been used to improve this important trait (Grobbel, 2008). However, with this improvement in tenderness, there is a chance that bacteria present on the meat's surface can be transferred to the interior during these processes (Sporing, 1999; Phebus et al., 2000; Sutterfield, 2008). Luchansky et al. (2009) concluded that bacterial translocation resulting from blade tenderization occurs primarily in the top portion of the meat, and it is not a food safety concern if the meat is cooked to at least a rare degree of doneness.

Needle-free injection technology has been used effectively in the livestock industry to administer vaccines to livestock (Houser et al., 2004; Hollis et al., 2005; Mousel et al., 2008). Houser et al. (2004) has suggested that vaccinating livestock with needle-free technology in place of traditional needle injections would be beneficial because it would eliminate the occurrence of needle fragments in carcasses. Sutterfield (2008) used needle-free technology to injection enhance meat. She evaluated its effect on microbial translocation of a high level of generic $E$. coli in beef strip loins. Her results actually showed that needle-free injection caused a slight increase $(P<0.05)$ in microbial translocation, which was approximately $0.8 \log \mathrm{CFU} / \mathrm{g}$. She concluded that, given the high level of inoculation used in her study, the difference between microbial translocation of needle and needle-free injection enhanced beef strip loins was "arguably insignificant in microbiological terms."

Because Sutterfield (2008) found needle-free injection enhancement to be relatively similar to traditional needle injection enhancement with regard to food safety, it needed to be evaluated for its effects on meat color, instrumental tenderness, sensory traits 
and yields. Therefore, the objectives of my research were to determine the effects of needle-free versus needle injection methods and/or solutions for enhancement of beef longissimus lumborum muscle on meat color, instrumental tenderness, sensory traits, pump yields, and cooking losses. 


\section{Materials and Methods}

\subsection{Preliminary Study}

In order to determine the optimal injection pressure (pounds per square inch (psi)) to be used for needle-free injection, preliminary research was conducted. Longissimus muscles $(\mathrm{n}=5)$ from USDA Select carcasses were obtained from a commercial abattoir at 4-5 days postmortem and then transported to Kansas State University where they were stored at $2^{\circ} \mathrm{C}$ for an additional 9-10 days. Muscles were divided into four sections and assigned to one of seven treatments with sterile colored saline solution: 1) 90 psi; 2) 55 psi; 3) $50 \mathrm{psi}$;) $45 \mathrm{psi}$ 5) $30 \mathrm{psi}$ 6) $25 \mathrm{psi}$; or 7) $20 \mathrm{psi}$. The sterile saline solution was mixed with blue food-grade coloring so that the dispersion of the solution could be tracked throughout the product after injection. Slices approximately $0.6 \mathrm{~cm}$ thick were made through the muscles for visual evaluation of depth, uniformity and extensiveness of the injection enhancement solution. The optimal psi was selected based on dispersion, visual appraisal, and penetration level. We determined that 25 psi was the best choice due to the greatest distribution, the absence of injection 'channels' (which were found in all psi levels above 30), and the deepest penetration (Fig. 2.1 contains examples of injection distributions).

Needle-free injection enhancements were made $0.95 \mathrm{~cm}$ apart in a grid pattern, using a plexiglass template, at a psi of 25 . In a preliminary trial, I was not able to achieve the desired pump yield using the plexiglass template with injections from only one side of the loin. We attribute this to unanticipated draining and waste of the solution during the injection process. We found that we were able to achieve pump yields of approximately $12 \%$ by injecting the loins from both sides. 
Fig. 2.1 Photographs illustrating penetration and distribution of the sterile dye solution when loins were injected from the lean side only.

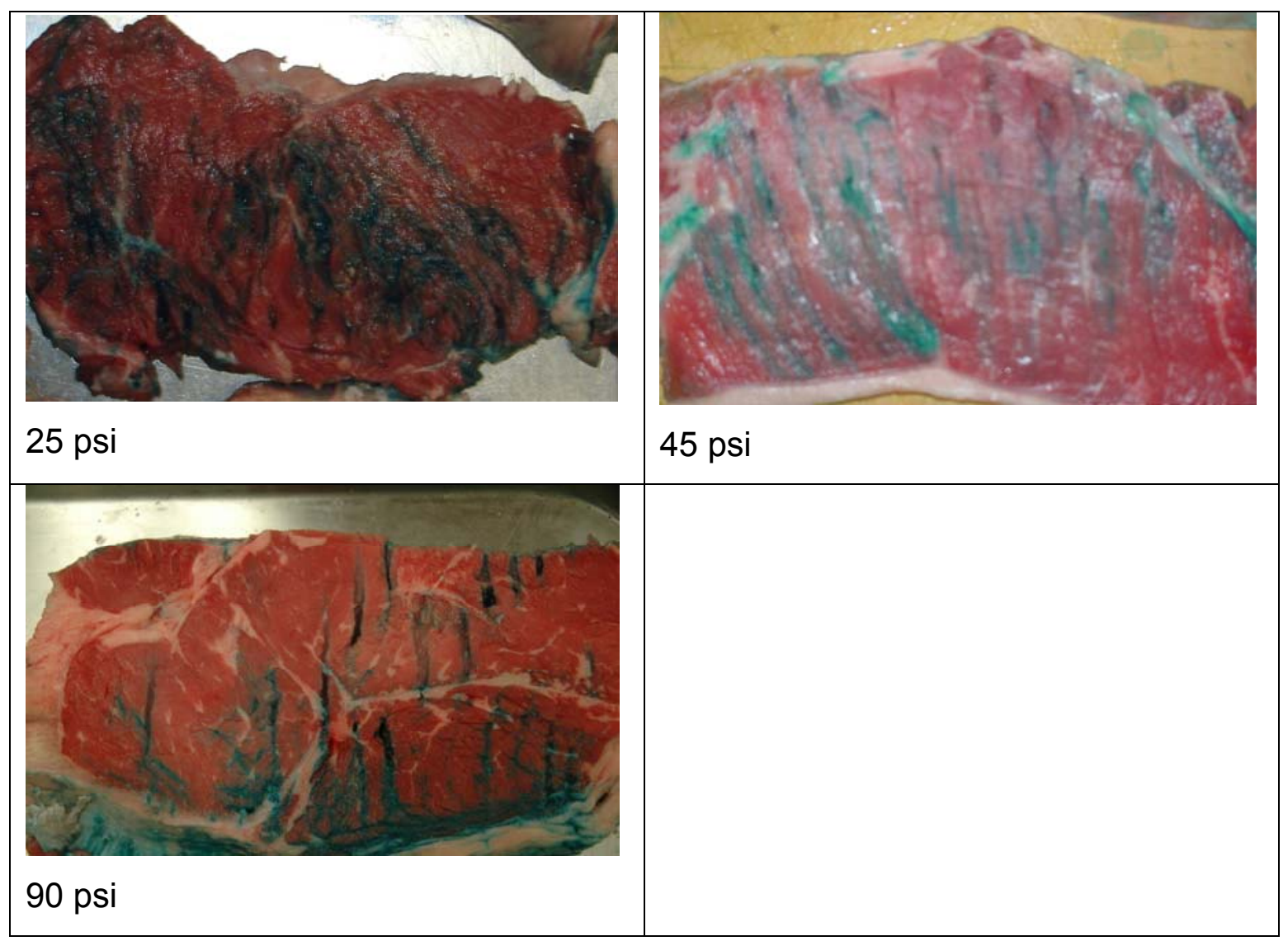

\section{Experiment 1}

\subsection{Samples and Injection}

Beef longissimus muscles $(\mathrm{N}=15)$ from USDA Select, A-maturity carcasses were obtained from a commercial abattoir at 2 days postmortem and transported to the Kansas State University Meat Laboratory where they were stored $\left(2^{\circ} \mathrm{C}\right)$ until 9 days postmortem. The fat was trimmed to $0.32 \mathrm{~cm}$, and each loin was halved and randomly assigned to one of two treatments: 1) needle $(\mathrm{N})$ injected (Model N30, Wolftec Inc., Werther, Germany), or 2) needle-free (NF) injected (Pulse Needle-Free Systems, Lenexa, KS). A plexiglass template, with holes at a distance of $0.95 \mathrm{~cm}$, was used to space the injection sites for NF injection. The NF injection was done using my pre-determined optimal setting of 25 psi. 
Both sides of the loins were injected in the NF treatment. This was based on my preliminary trials that showed the necessity of injecting both sides in order to achieve the desired pump yield. The needles on the $\mathrm{N}$ injector were spaced $1.77 \mathrm{~cm} \mathrm{x} 2.54 \mathrm{~cm}$ apart. The $\mathrm{N}$ injection was set to achieve a desired pump yield of $12 \%$. Needle injections were made from the fat side only to simulate what is commonly done in industry. A solution containing 2.2\% salt, 4.4\% sodium tripolyphospate (Brifisol 85 Instant, BK Giulini Corp., Simi Valley, CA) and 1.5\% K lactate (PURASAL Hipure P; PURAC America, Inc., Lincolnshire, IL) was used for injections.

\subsection{Pump Yields}

Each muscle section was weighed prior to injection (initial weight). After injection, each muscle section was placed on a wire rack and allowed to drain for $30 \mathrm{~min}$ before a final weight was taken. Pump yield was calculated by [(final weight - initial weight) / initial weight]*100.

\subsection{Packaging}

After the striploins were injected, four steaks $(2.54-\mathrm{cm}$ thick) were cut from the anterior end of each muscle section. Two of these steaks were placed in separate styrofoam trays and covered with polyvinyl chloride film to be placed into simulated retail display and evaluated for visual color. The remaining two steaks from each muscle section were vacuum packaged (VP; $62.2 \mathrm{~cm} \mathrm{Hg} \mathrm{vac;} \mathrm{Multivac} \mathrm{C500;} \mathrm{Multivac} \mathrm{Inc.,}$ Kansas City, MO), one of which was stored at $2{ }^{\circ} \mathrm{C}$ for 4 days while it awaited longissimus slice shear force measurements while the other was frozen at $-20^{\circ} \mathrm{C}$ for later sensory analysis. 


\subsection{Display Case and Color Measurements}

Steaks for visual color evaluation were displayed (Unit model DMF8, Tyler Refrigeration Corp., Niles, MI) under continuous fluorescent lighting (2153 lux, $3000 \mathrm{~K}$ and $\mathrm{CRI}=85$, Bulb model F32T8/ADV830/Alto, Philips, Bloomfield, NJ) for $5 \mathrm{~d}$ at $2^{\circ} \mathrm{C}$. Packages were rotated once daily in order to maintain a random sample placement.

Trained visual color panelists $(n=8)$ evaluated initial color on day 0 of display, and display color and surface discoloration were measured daily on days 1 to 5 of display. Initial color was determined using the following scale: 1) purplish pink or red or reddish tan, 2) bleached, pale red, 3) slightly cherry red, 4) moderately light cherry red, 5) cherry red, 6) slightly dark red, 7) moderately dark red, 8) dark red, and 9) very dark red. The color scale used by panelists after day 0 was: 1) very bright red, 2) bright red, 3) dull red, 4) slightly dark red, 5) slightly dark red or reddish tan, 6) moderately dark red to tannish red, and 7) tan to brown. On day 1 to 5, discoloration scores were recorded, which were considered as a percentage of surface metmyoglobin, and the following scale was used to evaluate this: 1) none (0\%), 2) slight discoloration (1-19\%), 3) small discoloration (20$39 \%), 4)$ modest discoloration $(40-59 \%), 5)$ moderate discoloration $(60-79 \%), 6)$ extensive discoloration (80-99\%), and 7) total discoloration (100\%). Color scales were used to half-point increments, and discoloration was scored to whole-point increments.

\subsection{Longissimus Slice Shear Force Measurements}

On day 13 postmortem, steaks were taken from the $2^{\circ} \mathrm{C}$ storage environment and cooked for longissimus slice shear force measurements. Steaks were cooked in a forcedair convection oven (Blodgett, model DFG-102 CH3, G.S. Blodgett Co., Burlington, VT) set at $163.0^{\circ} \mathrm{C}$. Steaks were turned at $40^{\circ} \mathrm{C}$ and cooked to an internal temperature of $70^{\circ} \mathrm{C}$, as monitored with copper-constantan thermocouples in the approximate geometric center of each steak.

Within 1 to 2 min after cooking, a 1-cm-thick, 5-cm-long slice was removed from the lateral end of each steak parallel to the muscle fibers. The slice was sheared perpendicular to the muscle fibers using an Instron Universal Testing Machine (model 4201, Instron Corp., Canton, MA) with a flat, blunt-end blade (thickness $1.016 \mathrm{~mm}$, cutting 
edge beveled to a half-round) and a crosshead speed of $500 \mathrm{~mm} / \mathrm{min}$. Peak shear force was recorded in $\mathrm{kg}$.

\subsection{Cooking Loss}

Steaks used for longissimus slice shear force measurements were weighed prior to cooking (initial weight), allowed to cool for approximately $5 \mathrm{~min}$ at room temperature, and weighed again (final weight). Cooking loss was calculated by [(initial weight - final weight) / initial weight]*100.

\subsection{Sensory Analysis}

Panelists $(\mathrm{n}=8)$ were trained according to AMSA guidelines (1995) for evaluation of steaks. Steaks were thawed overnight $\left(2^{\circ} \mathrm{C}\right)$, cooked to $70^{\circ} \mathrm{C}$ internally, sliced into $2.54 \mathrm{~cm} \times 1.27 \mathrm{~cm} \times 1.27 \mathrm{~cm}$ samples, and served warm to panelists. Samples were kept warm in blue enamel double boiler pans with warm water in the bottom pan. Panelists evaluated samples in duplicate for myofibrillar tenderness, juiciness, beef flavor intensity, amount of connective tissue, overall tenderness, and off-flavor using an eightpoint scale. The scale used for myofibrillar and overall tenderness was, 1) extremely tough, 2) very tough, 3) moderately tough, 4) slightly tough, 5) slightly tender, 6) moderately tender, 7) very tender, and 8) extremely tender. For juiciness, the scale was 1) extremely dry, 2) very dry, 3) moderately dry, 4) slightly dry, 5) slightly juicy, 6) moderately juicy, 7) very juicy, and 8) extremely juicy. The scale used for beef flavor was, 1) extremely bland, 2) very bland, 3) moderately bland, 4) slightly bland, 5) slightly intense, 6) moderately intense, 7) very intense, and 8) extremely intense. The scale used for connective tissue and off flavor intensity was, 1) abundant, 2) moderately abundant, 3) slightly abundant, 4) moderate, 5) slight, 6) traces, 7) practically none, and 8) none. Scores were given to the nearest half-point increment. 


\section{Experiment 2}

\subsection{Samples and Injection}

For each of two replications on two separate days, beef longissimus muscles $(\mathrm{N}=14)$ from USDA Select, A-maturity carcasses were obtained from a commercial abattoir at 2 days postmortem and transported to the Kansas State University Meat Laboratory where they were stored $\left(2^{\circ} \mathrm{C}\right)$ until 5 days postmortem. The fat was trimmed to $0.32 \mathrm{~cm}$, and each strip loin was halved and randomly assigned to one of four treatments: 1) needle $(\mathrm{N})$ injected (Model N30, Wolftec Inc., Werther, Germany) with a solution containing $2.4 \% \mathrm{Ca}$ lactate (PURACAL® PP/USP, PURAC America, Inc., Lincolnshire, IL) and 0.58\% rosemary (Nature-Guard B; Newly Weds Foods, Chicago, IL); 2) Needle-free (NF) injected (Pulse Needle-Free Systems, Lenexa, KS) with a solution containing $2.4 \%$ Ca lactate and $0.58 \%$ rosemary; 3) $\mathrm{N}$ injected with a solution containing 4.4\% sodium tripolyphosphate (STPP) (Brifisol 85 Instant, BK Giulini Corp., Simi Valley, CA), 2.2\% salt, 15\% K lactate (PURASAL Hipure P; PURAC America, Inc., Lincolnshire, IL), and $0.58 \%$ rosemary; or 4) NF injected with a solution containing $4.4 \%$ STPP, $2.2 \%$ salt, $15 \% \mathrm{~K}$ lactate, and $0.58 \%$ rosemary. A plexiglass template, with holes at a distance of $0.95 \mathrm{~cm}$, was used to space the injection sites for NF injection. The NF injection was done using the pre-determined optimal setting of 25 psi. Both sides of the loins were injected in the NF treatment. This was based on the preliminary trials that showed the necessity of injecting both sides in order to achieve the desired pump yield of $12 \%$. The needles on the $\mathrm{N}$ injector were spaced $1.77 \mathrm{~cm} \times 2.54 \mathrm{~cm}$ apart. The $\mathrm{N}$ injection was set to achieve a desired pump yield of $12 \%$. Needle injections were made from the fat side only to simulate what would be commonly done in industry.

\subsection{Pump Yields}

Each muscle section was weighed prior to injection (initial weight). After injection, each muscle section was placed on a wire rack and allowed to drain for 30 min 
before a final weight was taken. Pump yield was calculated by [(final weight - initial weight) / initial weight]*100.

\subsection{Packaging}

After the strip loins were injected, two steaks (2.54-cm thick) were cut from the anterior end of each muscle section. These steaks were vacuum packaged (VP; $62.2 \mathrm{~cm}$ $\mathrm{Hg}$ vac; Multivac C500; Multivac Inc., Kansas City, MO), one of which was stored at $2{ }^{\circ} \mathrm{C}$ for 4 days while it awaited longissimus slice shear force measurements and the other was frozen at $-20^{\circ} \mathrm{C}$ for later sensory analysis.

\subsection{Longissimus Slice Shear Force Measurements}

On d 14 postmortem, steaks were taken from the $2^{\circ} \mathrm{C}$ storage environment and cooked for longissimus slice shear force measurements and cooking losses as described in Experiment 1.

\subsection{Sensory Analysis}

Sensory analysis using eight panelists and the same scoring system was conducted the same as described in Experiment 1.

\subsection{Statistical Analysis}

\section{Experiment 1}

The display color and discoloration data were analyzed as a split-plot design using the mixed model procedure (PROC MIXED) of SAS (SAS Institute, Inc., Cary, NC). Strip loin halves served as the experimental units. Fisher's least significant difference was used to determine differences between treatments. The fixed effects were treatment, day, and treatment $x$ day. Significance was determined at probability values of $\mathrm{P}<0.05$.

The sensory, cook loss, pump yield and slice shear force data were analyzed using a one-way analysis of variance (ANOVA) with injection method being the fixed effect. We used the PROC MIXED procedure in SAS. Strip loin halves served as the experimental units. Loin was the random effect. Fisher's least significant difference was 
used to determine differences between treatments. Significance was determined at probability values of $\mathrm{P}<0.05$.

\section{Experiment 2}

The experimental design was a two-way ANOVA with injection method and solution as the two fixed effects. Statistical analysis was done using PROC MIXED of SAS. Each striploin was halved, and halves served as the experimental unit. Day and striploin were the random effects. Fisher's least significant difference was used to determine differences among treatments; if there were differences, then t-tests were used to evaluate interactions between solution and injection method. Significance was determined at probability values of $\mathrm{P}<0.05$. 


\section{Results and Discussion}

\section{Experiment 1}

\subsection{Pump Yields}

Pump yields were not different ( $\mathrm{P}>0.05$ ) between treatments (Fig. 2.2), but there was a trend $(\mathrm{P}=0.08)$ toward higher pump yields for the NF treatment. Our preliminary trials revealed that, without injecting from both sides of the loin, pump yields were low. We found pump yields closer to our target when injecting from both sides of the loin. However, in experiment 1, pump yields for both treatment groups were higher than what we had targeted. Literature comparing $\mathrm{N}$ and $\mathrm{NF}$ injection enhancement for their effects on pump yields is not available.

Fig. 2.2 Pump yield for injection methods used

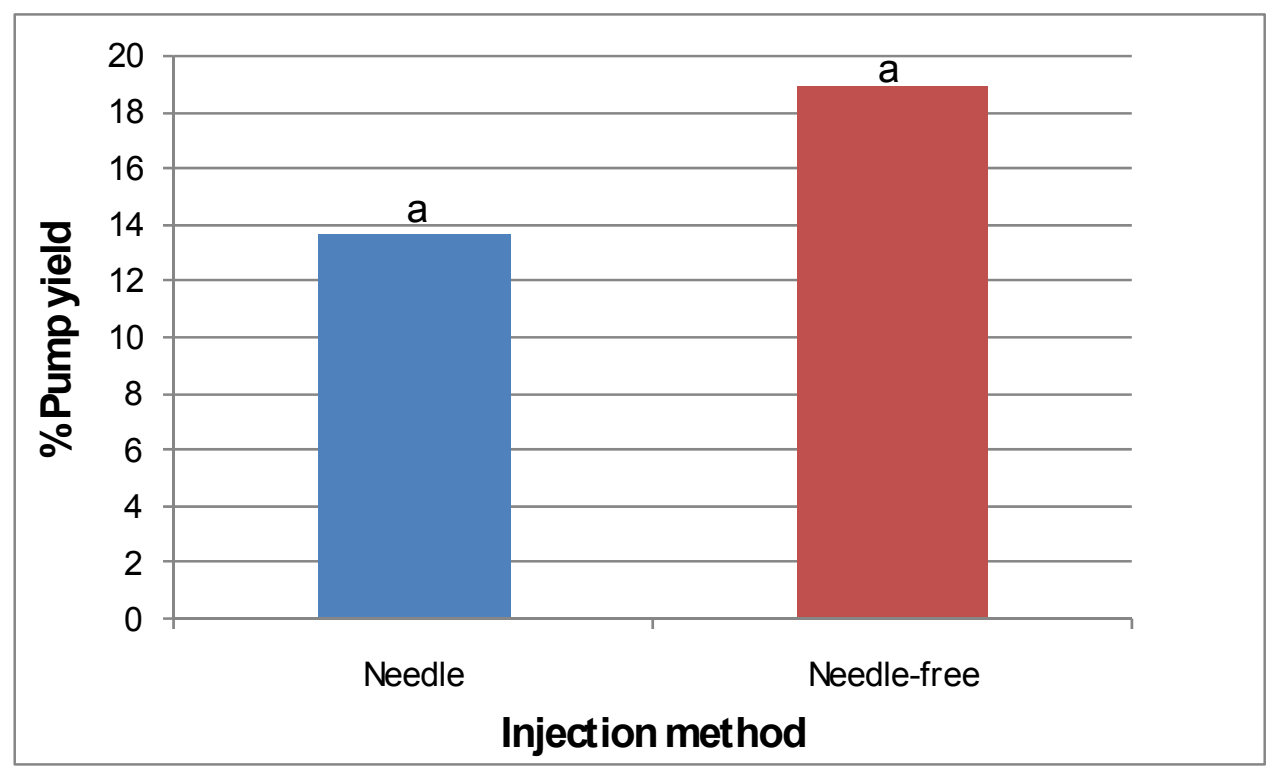

${ }^{\mathrm{a}}$ Means with different superscript letters differ $(P<0.05)$

Standard Error $=1.925$ 


\subsection{Display Color and Discoloration}

Injection method had no effect ( $\mathrm{P}>0.05)$ on initial color scores at day 0 (Fig. 2.3). Steaks from both treatments became darker $(\mathrm{P}<0.0001)$ as day of display increased, as expected (Fig. 2.4). There was a treatment $x$ day interaction $(\mathrm{P}<0.05)$ for visual color in which $\mathrm{N}$ injected steaks were darker on day 1 of display but not after day 1 (Fig. 2.4). There was no significant treatment or treatment $x$ day interaction $(\mathrm{P}>0.05)$ effect for discoloration scores (Fig. 2.5). As expected, discoloration scores indicated that steaks from both treatments had increasing amounts of discoloration as day of display increased $(\mathrm{P}<0.0001)$; the greatest increase occurred after day 3. Our results suggest that NF treatment improved visual color on day 1, but this advantage diminished after day 1 . There is no published literature on display color associated with NF injection enhancement.

Fig. 2.3 Initial (day 0) color score means for longissimus lumborum steaks for injection method used.

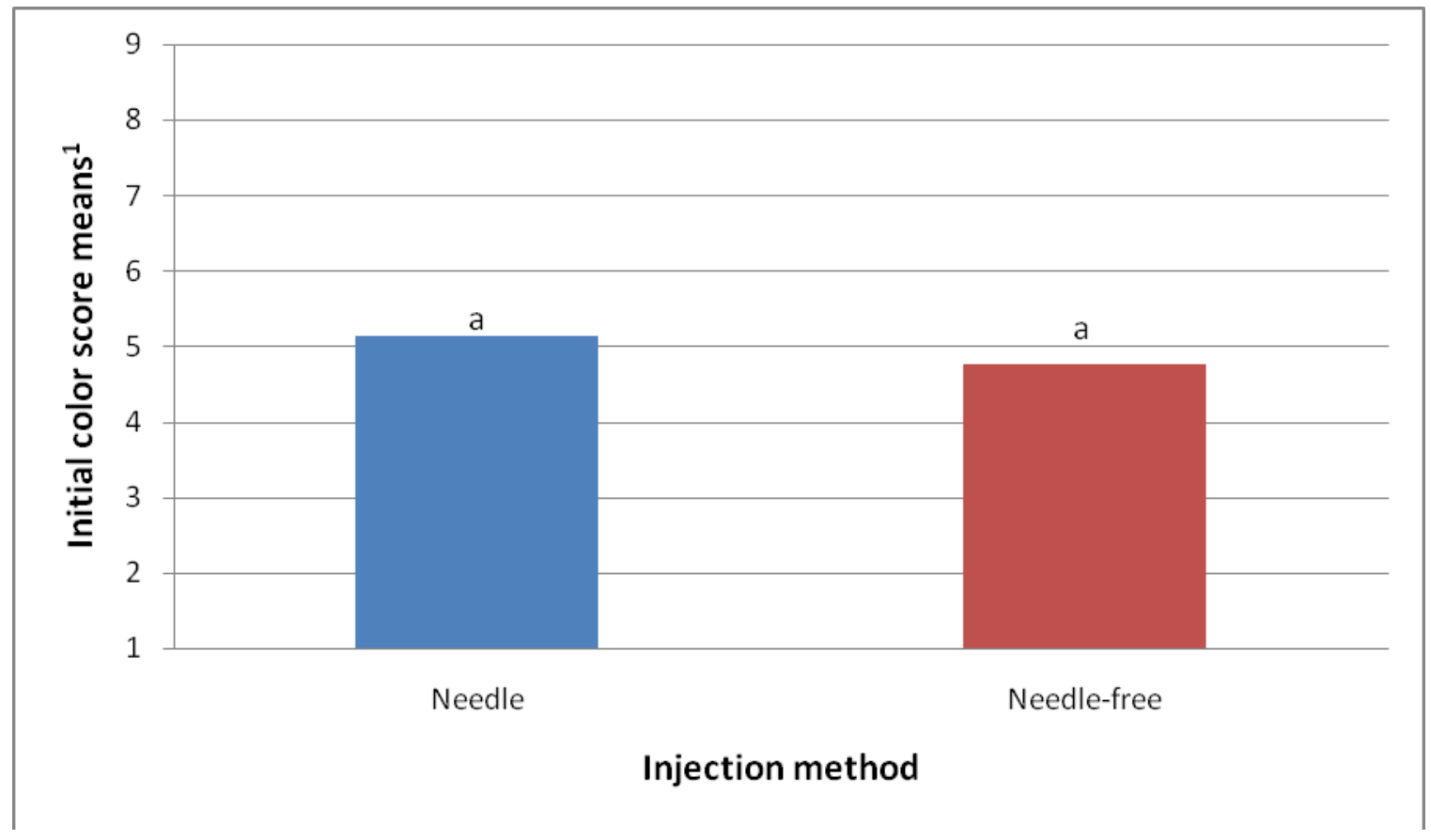

${ }^{1} 1=$ purplish pink or red or reddish tan of vacuum packages, $2=$ bleached, pale red, $3=$ slightly cherry red, $4=$ moderately light cherry red, $5=$ cherry red, $6=$ slightly dark red, 7 $=$ moderately dark red, $8=$ dark red, $9=$ very dark red

${ }^{a}$ Means with different superscripts letters differ $(P<0.05)$

Standard Error $=0.129$ 
Fig. 2.4 Color score means for needle (N) and needle-free (NF) injected longissimus lumborum steaks for days 1 through 5

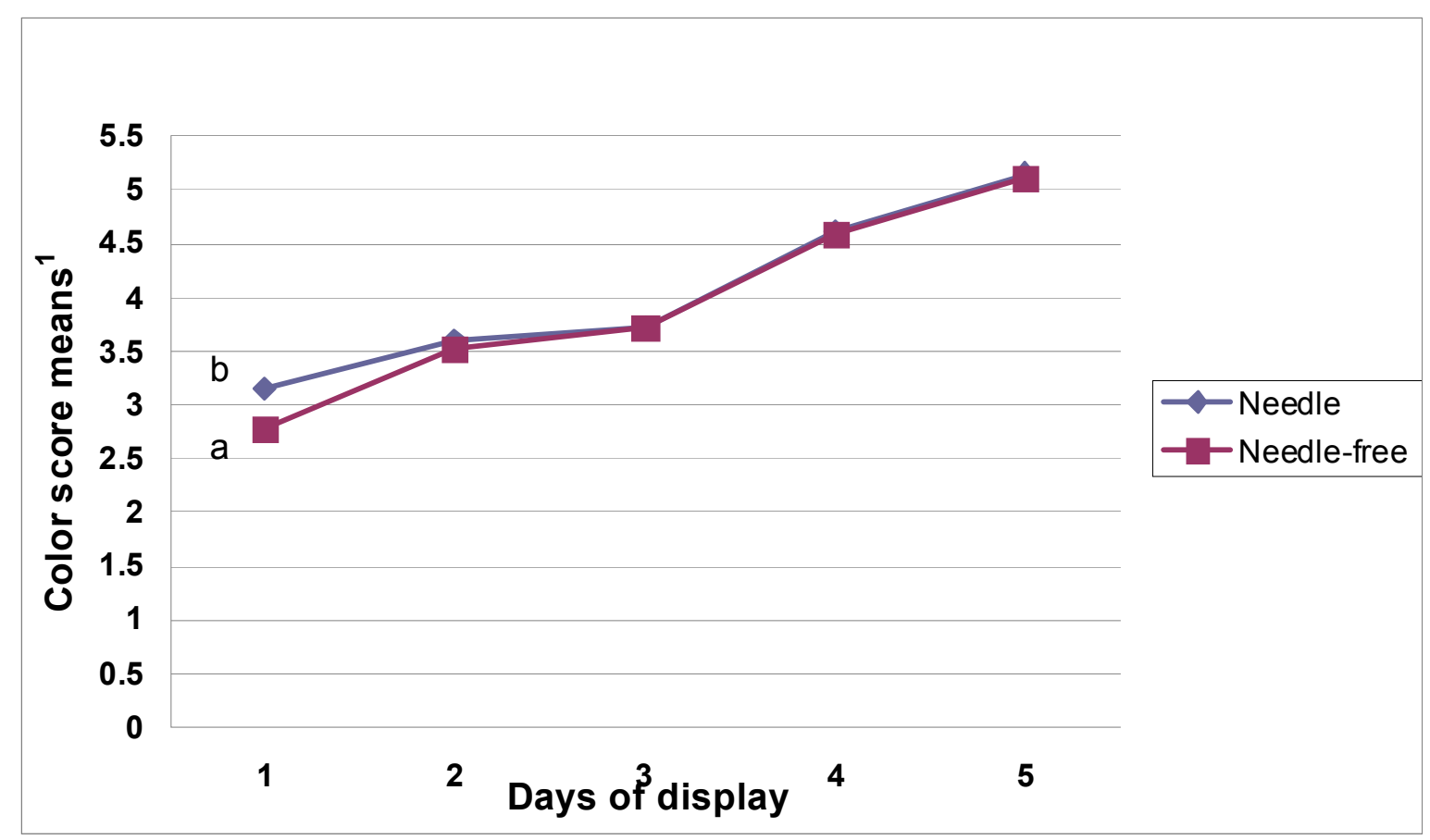

${ }^{1}$ Display color score $(1=$ very bright red, $2=$ bright red, $3=$ dull red, $4=$ slightly dark red, $5=$ slightly dark red or reddish tan, $6=$ moderately dark red to tannish red, $7=\tan$ to brown) means for longissimus steaks injection enhanced by either needle or needle-free technology.

${ }^{\mathrm{ab}}$ Means for a given day with different superscript letters differ $(P<0.05)$

Standard Error $=0.126$ 
Fig. 2.5 Discoloration means for needle (N) and needle-free (NF) injected longissimus lumborum steaks for days 1 through 5

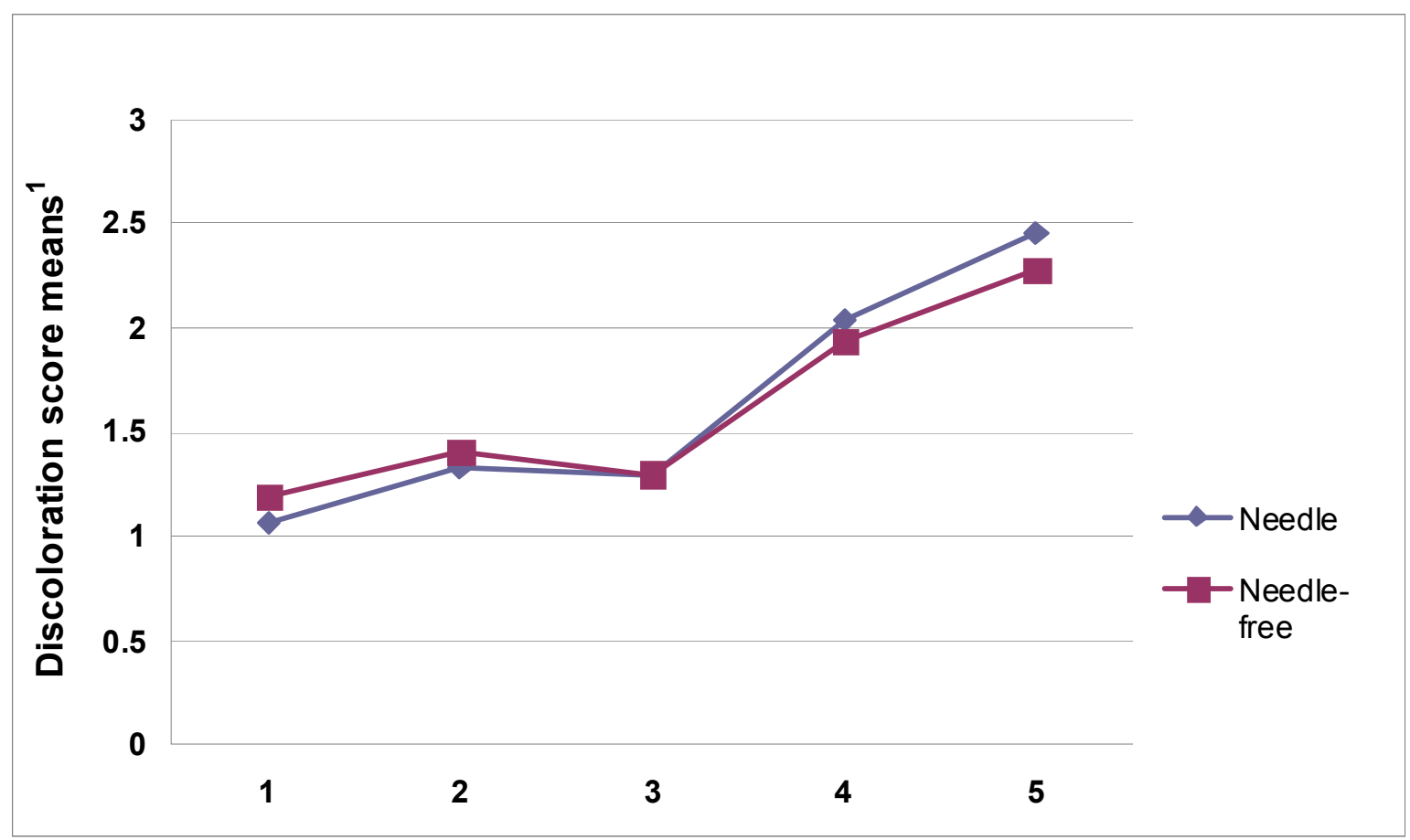

${ }^{1}$ Display discoloration score $(1=$ none $(0 \%), 2=$ slight discoloration $(1-19 \%), 3=$ small discoloration (20-39\%), $4=$ modest discoloration (40-59\%), $5=$ moderate discoloration $(60-79 \%), 6=$ extensive discoloration $(80-99 \%)$ and $7=$ total discoloration $(100 \%))$ means for longissimus steaks injection enhanced by either needle or needle-free technology.

Differences were not significant $(P>0.05)$.

Standard Error $=0.091$ 


\subsection{Longissimus Lumborum (LL) Slice Shear Force Measurements}

Longissimus lumborum slice shear force values indicate that all of our steaks were tender, but steaks from loins that were injected using the NF technology $(7.7 \mathrm{~kg})$ were more tender $(\mathrm{P}<0.05)$ than those from loins that were injected with the traditional $\mathrm{N}$ injector (10.1 kg) (Fig. 2.6). Given the closer spacing of NF injection sites and application of injection from both sides, an improvement from mechanical tenderization seems logical. However, the difference in the appearance of muscle structure between steaks from the two treatments was virtually unnoticeable at the 25 psi setting that was used. Although not significant, there was a trend $(\mathrm{P}=0.08)$ toward higher pump yields for the NF treatment, which could have also played a role in the higher tenderness of the NF steaks (Fig. 2.2). This seems in alignment with Baublits et al. (2005) who found that higher pump yields were associated with greater perceived tenderness. They used an enhancing solution very similar to mine.

Fig. 2.6 Longissimus lumborum slice shear force means for needle (N) and needle-free (NF) injection methods.

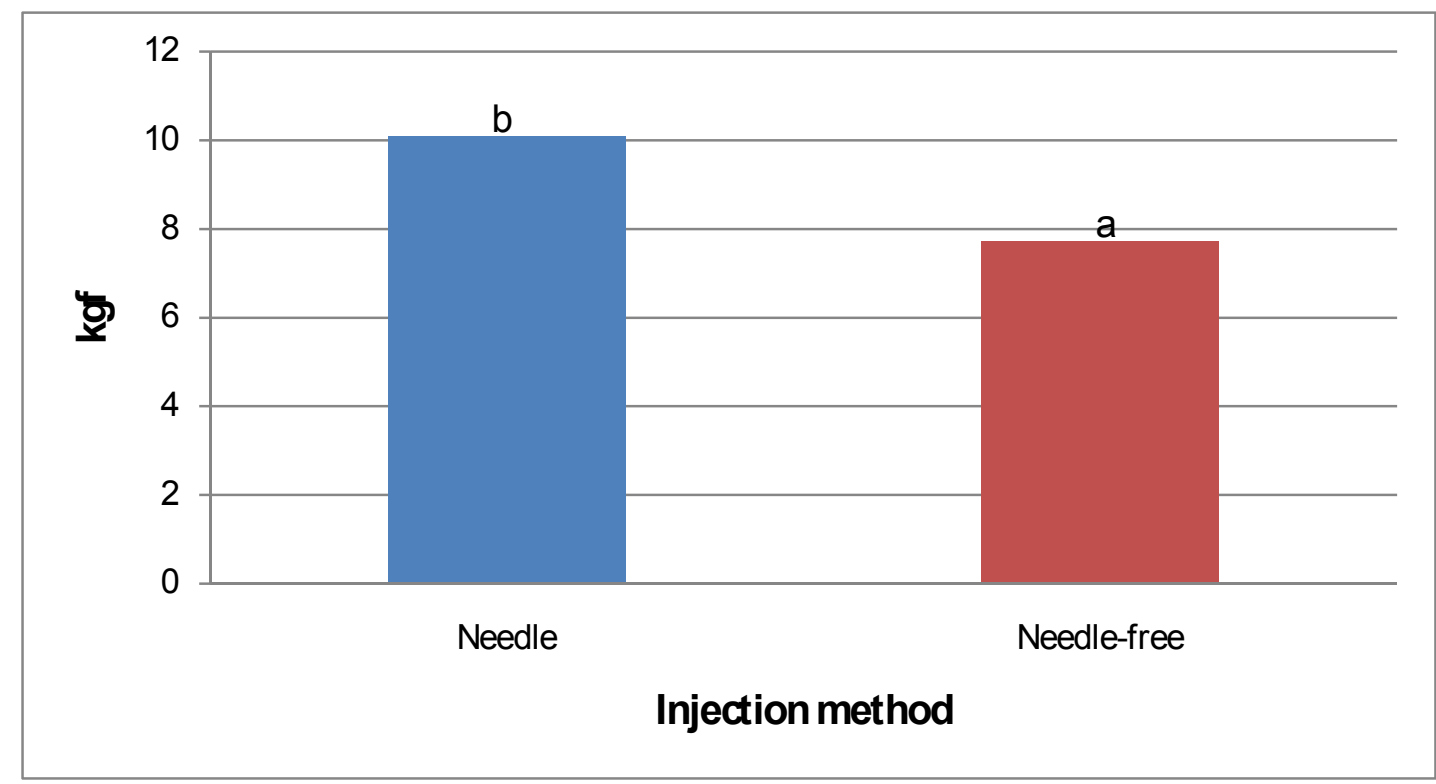

\footnotetext{
${ }^{\mathrm{ab}}$ Means with different superscript letters differ $(P<0.05)$

Standard Error $=0.700$
} 


\subsection{Cooking Losses}

Steaks from loins that had been injected with the NF device had less cooking loss $(\mathrm{P}<0.05)$ than those from loins injected with the $\mathrm{N}$ injector (Fig. 2.7) perhaps because there was a trend $(\mathrm{P}=0.08)$ toward higher pump yields with the NF treatment (Fig. 2.2). Baublits et al. (2006) found that higher pump yields resulted in higher cooking losses in their study, likely because the product had more moisture that could be lost in the cooking process. Oddly, an earlier study by Baublits et al. (2005) compared pump yields of $12 \%$ versus $18 \%$ and found no difference in cooking loss between the two treatments. With regard to my research, perhaps the better distribution of solution with NF injections that I suspect occurred (as a result of a greater number of penetrations) allowed phosphate to bind water more uniformly throughout the product and thus caused less cooking loss. If the NF injections resulted in a better distribution of solution into the product, my research could be compared with other research by Grobbel et al. (2008) where they concluded that phosphate increased the $\mathrm{pH}$ of enhanced steaks further from the isoelectric point and thus increased water-holding capacity, which reduced cooking loss. Cooking loss was reduced by injection enhancement with salt and phosphate in a study by Molina et al. (2005), so any increase in distribution of the enhancing solution throughout the meat that could have happened with NF injection in my study could logically reduce cooking loss within the NF treatment. 
Fig. 2.7 Cooking loss of longissimus lumborum steaks for injection methods.

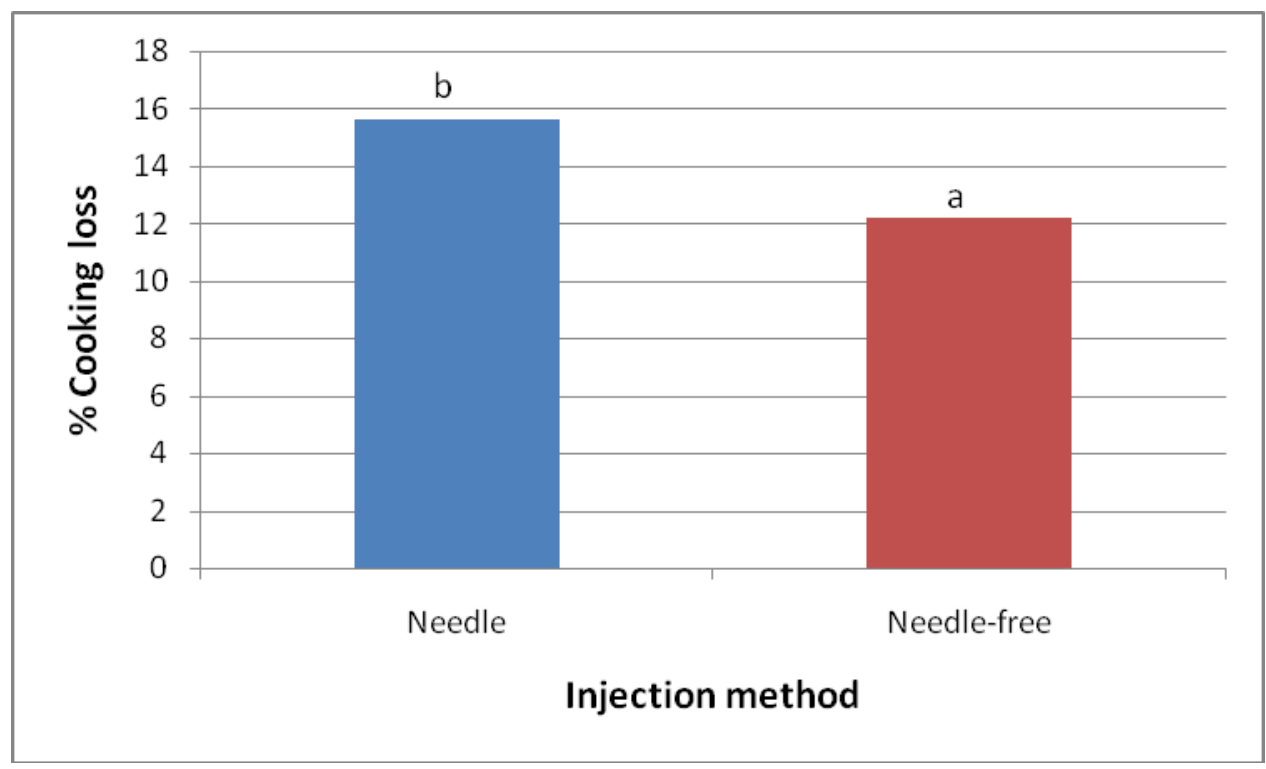

${ }^{\mathrm{ab}}$ Means with different superscript letters differ $(P<0.05)$

Standard Error $=0.659$ 


\subsection{Sensory Analysis}

According to trained sensory panelists, myofibrillar tenderness, juiciness, connective tissue amount, and overall tenderness were not different $(\mathrm{P}>0.05)$ between treatments (Fig. 2.8). Steaks from the NF treatment (3.6, $\mathrm{SE}=0.2)$ had less $(\mathrm{P}<0.05)$ beef flavor intensity than steaks from the $\mathrm{N}$ treatment (4.9, $\mathrm{SE}=0.2)$ (Fig. 2.8). Panelists also reported more $(\mathrm{P}<0.05)$ off flavors in the $\mathrm{NF}$ treatment $(3.9, \mathrm{SE}=0.2)$ versus the $\mathrm{N}$ treatment (5.1, SE=0.2). The most common off flavors reported were salty, soapy, livery or metallic. The salty, livery, and metallic descriptors were reported fairly evenly for both treatments, with the primary difference being that the intensity of the off-flavors was greater for the NF treatment. The soapy descriptor was used almost exclusively among the NF treatment. The salty off flavor was by far the most common descriptor, and both treatments received that descriptor on almost every sample. There were also a few comments indicating a slick, mushy texture of steaks from the NF treatment.

Both treatment groups seemed to have flavor and off-flavor scores that were undesirable. Grobbel et al. (2008) conducted a study where all enhanced steaks had more off-flavors than non-enhanced steaks. The mean off-flavor score for my $\mathrm{N}$ injected steaks was similar to off-flavor scores reported in their study. However, the mean off-flavor score for my NF treatment is clearly quite severe, which could be due to a higher distribution of the solution into the product. Again, the trend $(\mathrm{P}=0.08)$ toward higher pump yields for the NF treatment might also help explain these differences (Fig. 2.2). That would agree with the results of a study by Seyfert et al. (2005) where higher pump yields in injection enhanced beef round muscles resulted in more off-flavors. Perhaps the use of a higher level of $\mathrm{K}$ lactate in our brine would have helped improve beef flavor as it did in a study by Knock et al. (2006a). 
Fig. 2.8 Trained sensory panel scores for longissimus lumborum steaks injected by either needle (N) or needle-free (NF) methods.

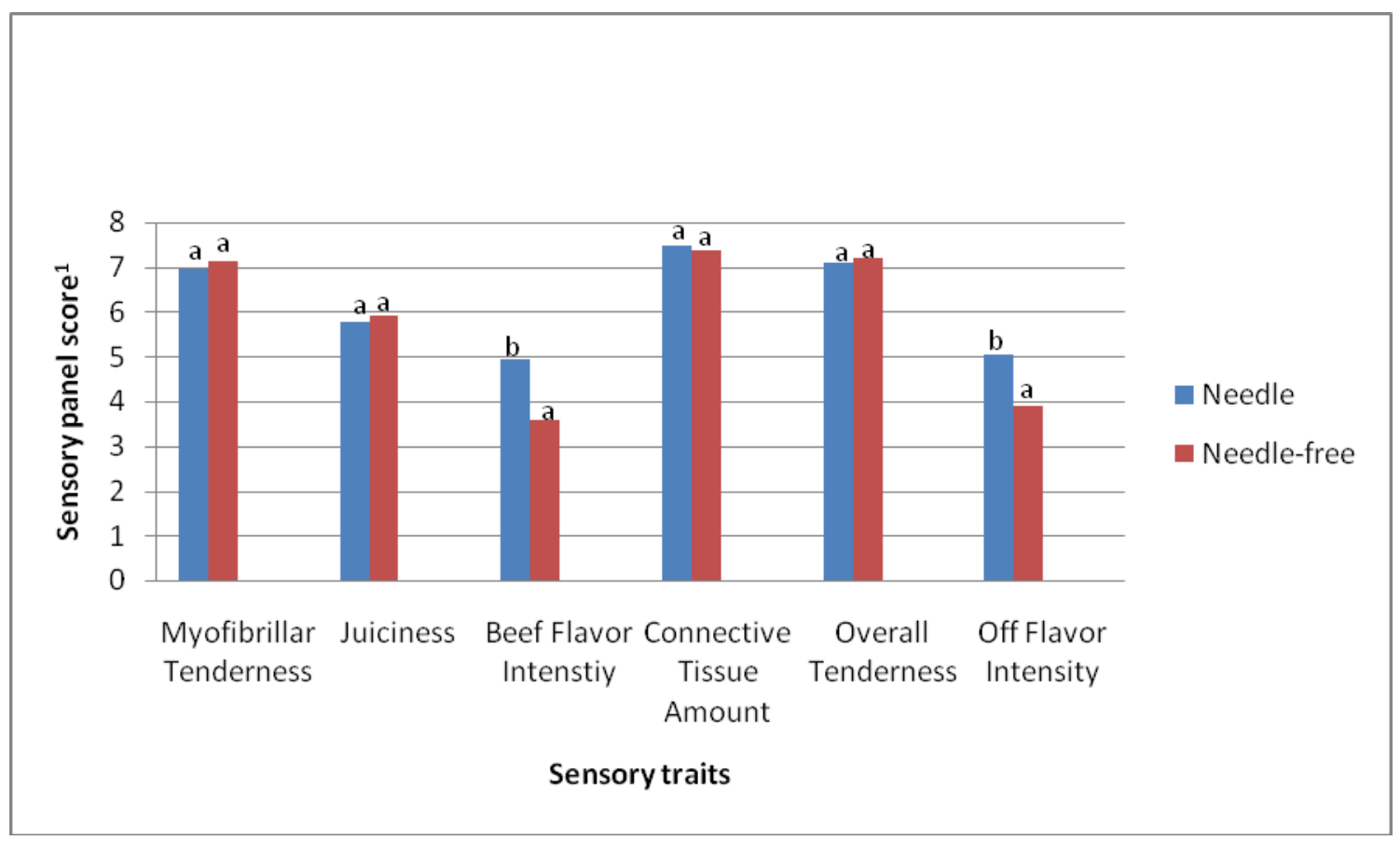

${ }^{1}$ myofibrillar and overall tenderness scale: $1=$ extremely tough, $4=$ slightly tough, $6=$ moderately tender, $8=$ extremely tender; juiciness scale: $1=$ extremely dry, $4=$ slightly dry, $6=$ moderately juicy, $8=$ extremely juicy; beef flavor intensity scale: $1=$ extremely bland, $4=$ slightly bland, $6=$ moderately intense, $8=$ abundant; connectivetissue amount scale: 1 = abundant, $4=$ moderate, $6=$ traces, $8=$ none; off flavor intensity scale: $1=$ abundant, $4=$ moderate, $6=$ traces, $8=$ none

${ }^{\mathrm{ab}}$ Means within a sensory trait with different superscript letters differ $(P<0.05)$

Standard Errors: Myofibrillar tenderness $=0.107$; Juiciness $=0.010$; Beef flavor intensity $=0.116$; Connective tissue amount $=0.068$; Overall tenderness $=0.010$; Offflavor intensity $=0.188$ 


\section{Experiment 2}

\subsection{Pump Yields}

There was a treatment $x$ solution interaction $(\mathrm{P}<0.05)$ for pump yields (Fig. 2.9). There was no difference $(\mathrm{P}>0.05)$ between $\mathrm{N}$ and $\mathrm{NF}$ treatments when the $\mathrm{Ca}$ lactate solution was used. Neither the N or NF loins injected with the Ca lactate solution had pump yields that differed from the $\mathrm{N}$ injected loins that were injected with the phosphate solution; however, the NF injected loins that were injected with the phosphate solution had pump yields that were higher $(\mathrm{P}<0.05)$ than all other treatment combinations (Fig. 2.9). Hoffman et al. (2006) stated that the role of various salts, particularly phosphates, for enhancing the water binding capacity of muscle is well known. Lawrence et al. (2004) found that enhancement with a phosphate and salt plus rosemary solution resulted in a higher pump yield than enhancement with a Ca lactate plus rosemary solution. My NF

treatment among the phosphate enhanced steaks yielded results that are in agreement with those of Lawrence et al. (2004), but my results as a whole differ in that there was no difference between injection solutions for our $\mathrm{N}$ treatment. 
Fig. 2.9 Pump yield for longissimus lumborum steaks injected by needle (N) or needle (NF) methods using either a calcium lactate or phosphate solution.

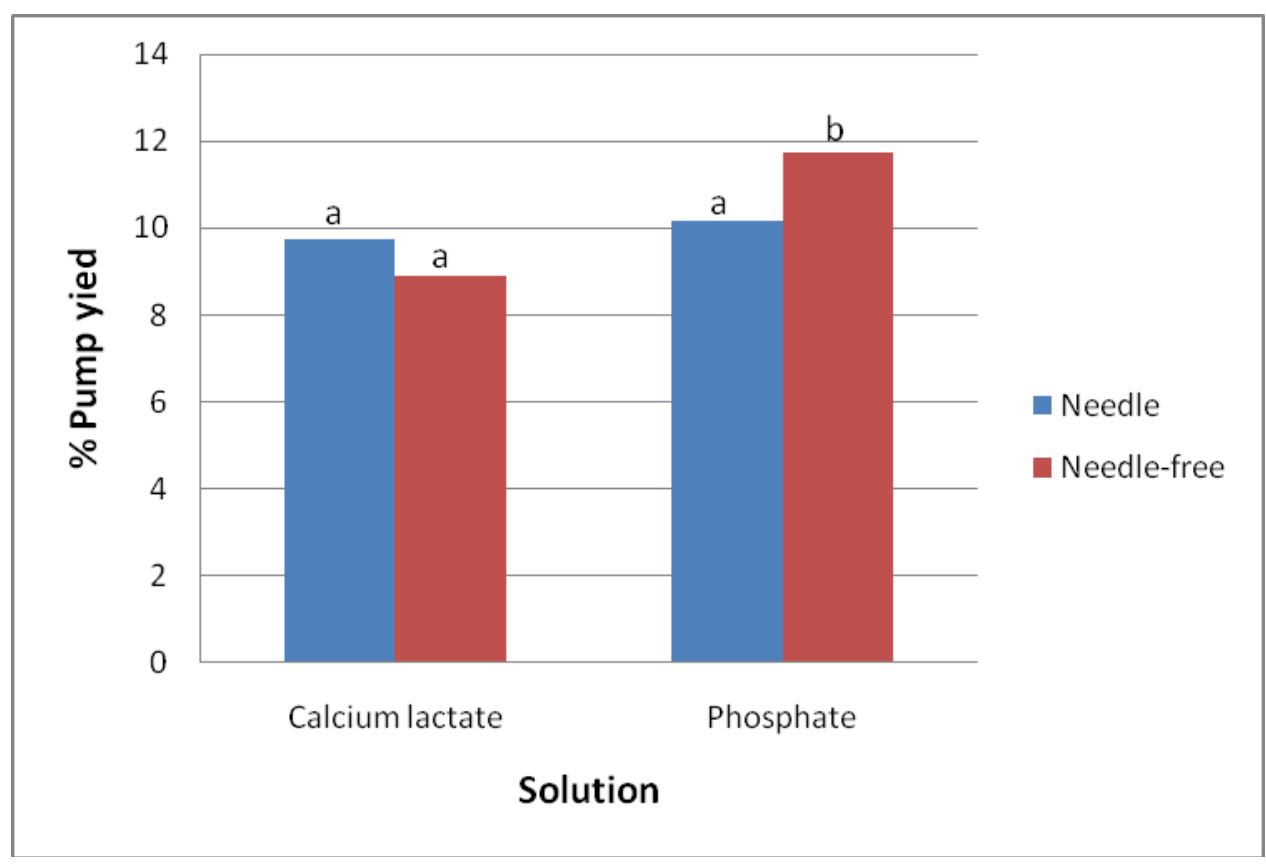

${ }^{\mathrm{ab}}$ Means with different superscript letters differ $(P<0.05)$

Standard Error $=0.581$

\subsection{Longissimus Lumborum (LL) Slice Shear Force Measurements}

There was no injection method treatment $x$ solution interaction $(\mathrm{P}=0.94)$ for longissimus slice shear force measurements. Steaks injected with the phosphate solution had slice shear force values that were lower $(\mathrm{P}<0.05)$ than those steaks injected with the Ca lactate solution (Fig. 2.10). There were no differences $(\mathrm{P}>0.05)$ between $\mathrm{N}$ and NF treatments, which contradicts the results I found in Experiment 1. The lower slice shear force values of steaks enhanced with the phosphate solution in my study can be compared with those of Lawrence et al. (2004) who compared solutions similar to mine and found no differences in Warner-Bratzler shear force (WBSF) values between treatments. In contrast, in their study panelists rated Ca lactate enhanced steaks lower for both myofibrillar and overall tenderness. They reported a weak correlation $(r=-0.36)$ between Warner-Bratzler peak force measurements and sensory panel overall tenderness scores. 
Lawrence et al. (2004) suggested that this could have resulted from unusually low WBSF values of the loins in their study, which might have heightened sensitivity of subjective observations over objective measures. However, steaks in my study had 8 days between enhancement and instrumental tenderness measurements whereas steaks in their study only had 4 days. I contend that my two-fold increase in marinating time allowed the solutions more time to have their maximum tenderizing effects and thus might account for this contrast in results. According to Grobbel et al. (2008), enhancing beef with a salt/phosphate solution improves tenderness by increasing water-binding, which consequently increases the space between muscle fibers. Enhancing beef with a $\mathrm{Ca}$ lactate solution improves tenderness by accelerating activation of the calpain enzymes to degrade Z-disk proteins, thereby weakening myofibrillar structure (Koohmaraie, 1994). 
Fig. 2.10 Longissimus lumborum slice shear force means for steaks injected by needle (N) or needle-free (NF) methods with either a calcium lactate or phosphate solution.

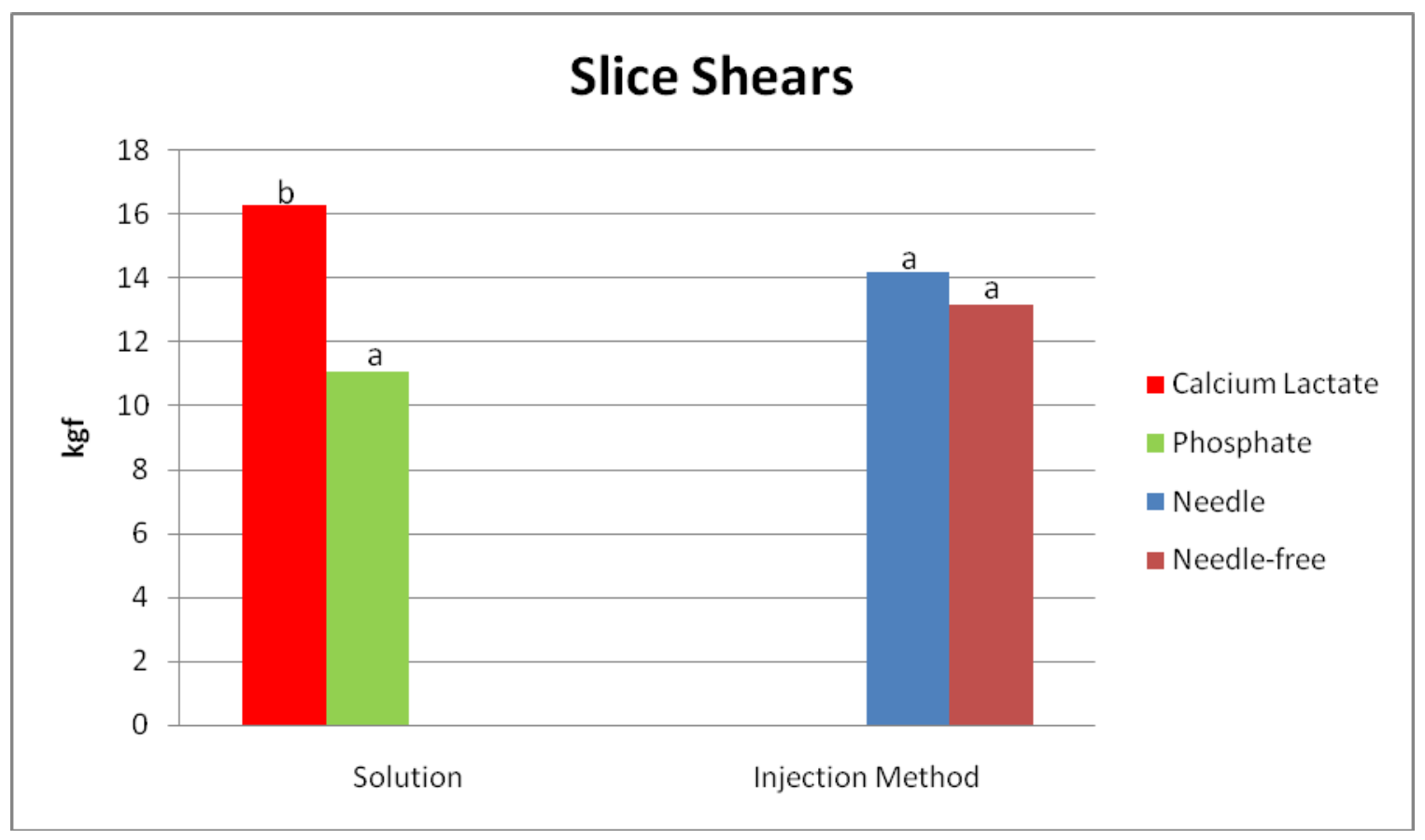

${ }^{\mathrm{ab}}$ Means within a category with different superscripts letters $\operatorname{differ}(P<0.05)$ Standard Error: Solution $=1.235$; Injection method $=1.201$ 


\subsection{Cooking Losses}

There was a treatment $x$ solution interaction $(\mathrm{P}<0.05)$ for cooking loss. There was no difference $(\mathrm{P}>0.05)$ between $\mathrm{N}$ and $\mathrm{NF}$ injections for loins that were injected with $\mathrm{Ca}$ lactate; however, those loins had a higher $(\mathrm{P}<0.05)$ cooking loss than loins injected with the phosphate solution (Fig. 2.11). Figure 2.11 shows that the NF injected loins that were enhanced with the phosphate solution had the lowest $(\mathrm{P}<0.05)$ cook loss of any treatment combination. However, the NF injected loins that were phosphate-enhanced also had the highest pump yield of any treatment combination (Fig. 2.9), which could account for at least part of this difference. It is not surprising that the phosphate solution was more effective at lowering cooking loss. That concept is in full agreement with a study by Lawrence et al. (2004) where longissimus muscles injected with a phosphate and salt plus rosemary solution had a higher $\mathrm{pH}$ and water binding ability than those enhanced with a $\mathrm{Ca}$ lactate plus rosemary solution. The Ca lactate solution in their study had a $\mathrm{pH}$ of 6.0 while their phosphate solution had a $\mathrm{pH}$ of 6.8. The solutions that I used were very similar to those of Lawrence et al. (2004) with regard to both content and concentrations of each ingredient. 
Fig. 2.11 Cooking loss for longissimus lumborum steaks injected by needle (N) or needle-free (NF) methods using either the calcium lactate or phosphate solution.

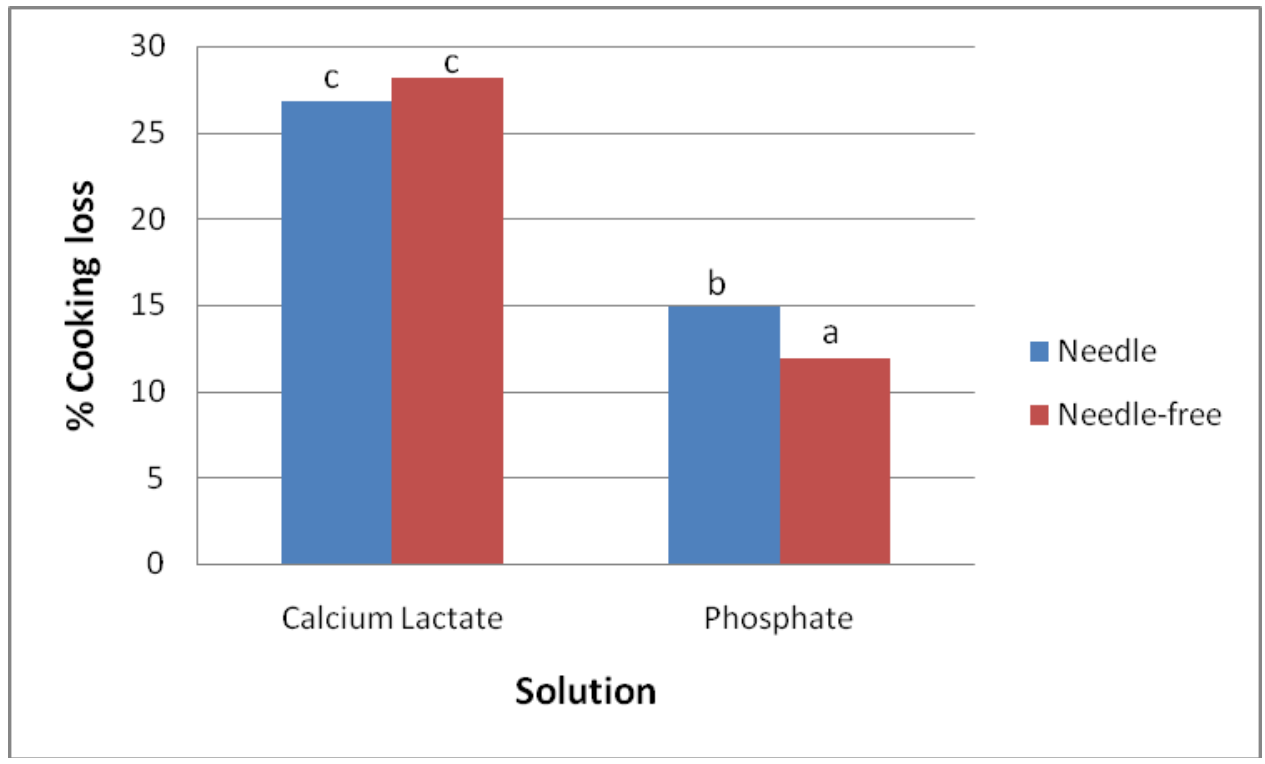

${ }^{\mathrm{abc}}$ Means with different superscript letters differ $(P<0.05)$

Standard Error: 1.055 


\subsection{Sensory Analysis}

There were no treatment $x$ solution interactions $(\mathrm{P}>0.05)$ for any of the sensory traits. Panelists detected no differences $(\mathrm{P}>0.05)$ between $\mathrm{N}$ and NF treatments for myofibrillar tenderness, juiciness, beef flavor intensity, connective tissue amount, and overall tenderness. However, off-flavor intensity scores were higher $(\mathrm{P}<0.05)$ (fewer offflavors) for the $\mathrm{N}$ injected steaks (Fig. 2.12). The most common off-flavor descriptors reported were salty, bitter, sour, soapy, chemical, acid, metallic, and livery. Salty was easily the most common off-flavor, and it was far more common to loins that had been injected with the phosphate solution, which contained 2.2\% salt whereas the Ca lactate solution did not contain any salt; so this was no surprise. Soapy off-flavors were more prevalent among the NF injected steaks. Other off-flavor descriptors seem evenly distributed between N and NF treatments. Bitter, sour, acid, and metallic descriptors of off-flavors were more common among loins injected with Ca lactate. Texture scores were higher $(\mathrm{P}<0.05)$ among $\mathrm{N}$ injected steaks, meaning that panelists perceived the texture of $\mathrm{N}$ injected steaks to be closer to that of normal non-enhanced steaks (Fig. 2.12). The most common descriptors for abnormal texture were mealy, gelatin, crunchy, slick, or mushy. The distribution of these descriptors seems fairly even between injection methods; the difference was in the intensity of the abnormality. However, the "gelatin" descriptor was far more common among steaks enhanced with the phosphate solution while steaks enhanced with the calcium lactate solution more commonly received a "mealy" texture descriptor. Grobbel et al. (2008) found that enhanced steaks had more off-flavors than non-enhanced steaks with typical descriptors of salty or metallic or chemical. If the NF injected steaks had the better solution distribution that I suspect (due to a greater number of penetrations per surface area), the more intense off-flavors among NF enhanced steaks seems in alignment with the results of Grobbel et al. (2008), who also found unusual mushy texture similar to what panelists in my study reported. 
Fig. 2.12 Trained sensory panel scores for longissimus lumborum steaks injected by needle (N) or needle-free (NF) methods.

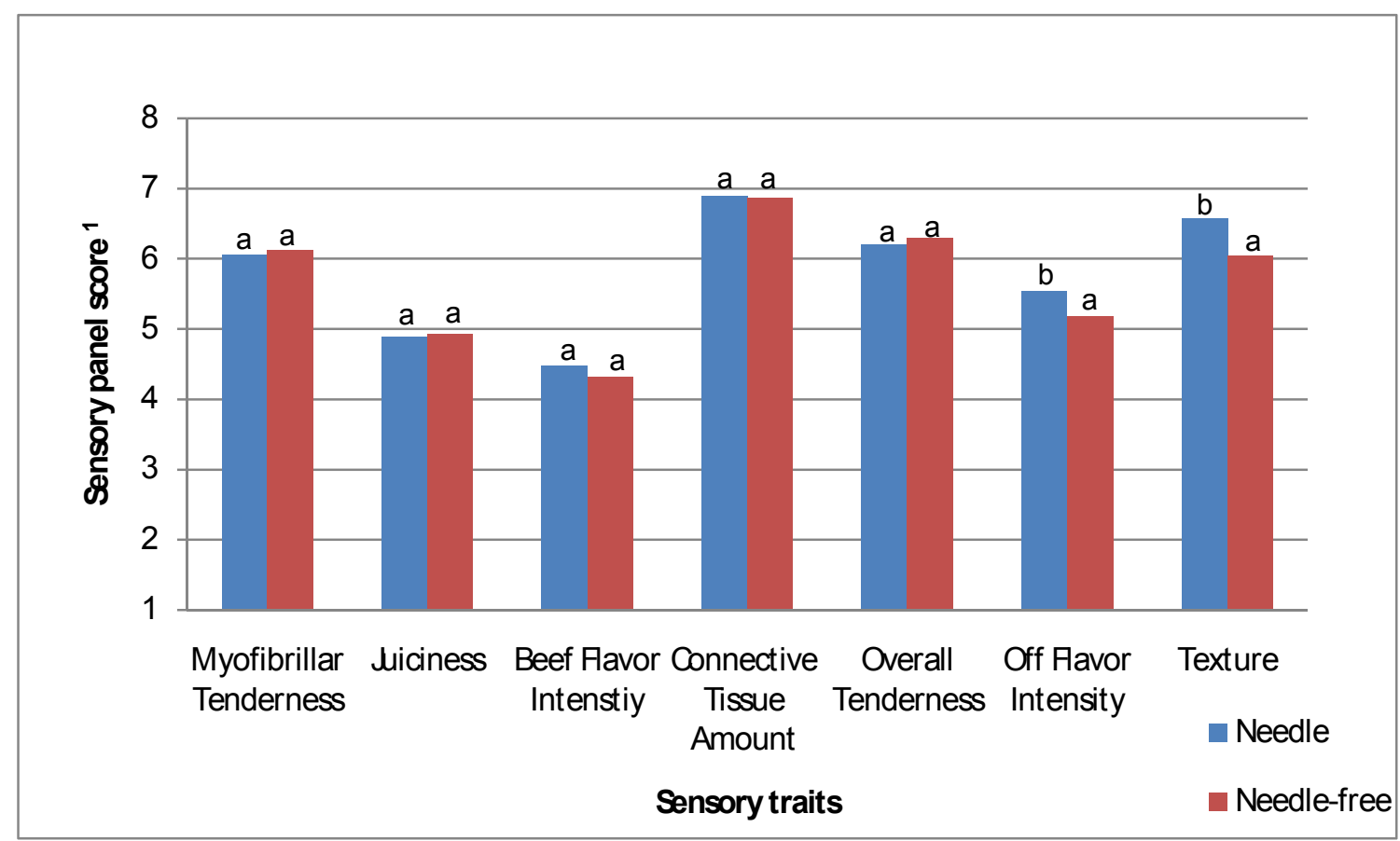

${ }^{1}$ myofibrillar and overall tenderness scale: $1=$ extremely tough, $4=$ slightly tough, $6=$ moderately tender, $8=$ extremely tender; juiciness scale: $1=$ extremely dry, $4=$ slightly dry, $6=$ moderately juicy, $8=$ extremely juicy; beef flavor intensity scale: $1=$ extremely bland, $4=$ slightly bland, $6=$ moderately intense, $8=$ abundant; connectivetissue amount scale: $1=$ abundant, $4=$ moderate, $6=$ traces, $8=$ none; off flavor intensity scale: $1=$ abundant, $4=$ moderate, $6=$ traces, $8=$ none; texture scale: $1=$ extremely abnormal, $4=$ slightly abnormal, $6=$ moderately normal, $8=$ extremely normal

abMeans within a sensory trait with different superscript letters differ $(P<0.05)$

Standard Errors: Myofibrillar tenderness $=0.101$; Juiciness $=0.116$; Beef flavor $=0.083$; Connective tissue $=0.106$; Overall tenderness $=0.112$; Off-flavors $=0.121 ;$ Texture $=$ 0.123 
Myofibrillar tenderness, juiciness, connective tissue amount, and overall tenderness were scored lower $(\mathrm{P}<0.05)$ for the loins enhanced with the Ca lactate solution than those enhanced with the phosphate solution (Fig. 2.13). This means that panelists perceived the steaks enhanced with the phosphate solution to have greater myofibrillar tenderness, juiciness, and overall tenderness while having less abundant connective tissue. Beef flavor intensity was not different $(\mathrm{P}>0.05)$ between solutions. Off-flavor intensity scores and texture scores were higher $(\mathrm{P}<0.05)$ (fewer off-flavors and a more normal texture) for steaks enhanced with the Ca lactate solution (Fig. 2.13). When Lawrence et al. (2003) compared the effects of different calcium salts on beef longissimus quality, he determined that $\mathrm{Ca}$ lactate was the best from the standpoint of having fewer off-flavor problems, but even solution with Ca lactate still resulted in off-flavors.

The superior tenderness of loins injected with the phosphate solution is in agreement with the results of a study by Lawrence et al. (2004) where perceptive tenderness by trained panelists was rated lower for longissimus steaks that had been enhanced with Ca lactate plus rosemary than steaks enhanced with phosphate and salt plus rosemary. They also found results that coincide with my higher juiciness scores accompanying the phosphate and salt plus rosemary solution versus the Ca lactate plus rosemary solution. In their study, beef flavor intensity and off-flavor intensity scores were higher (more beef flavor and less abundant off-flavors) for the Ca lactate plus rosemary solution than the phosphate and salt plus rosemary solution. This matches my results for off-flavor intensity, but it is in slight contrast to my results for beef flavor intensity where I found no difference due to injection solution. Their results also agreed with mine in that panelists found less abundant perceptible connective tissue among the phosphate and salt plus rosemary enhanced steaks versus the Ca lactate plus rosemary enhanced steaks. 
Fig. 2.13 Trained sensory panel scores for longissimus lumborum steaks injection enhanced with either the calcium lactate or phosphate solution.

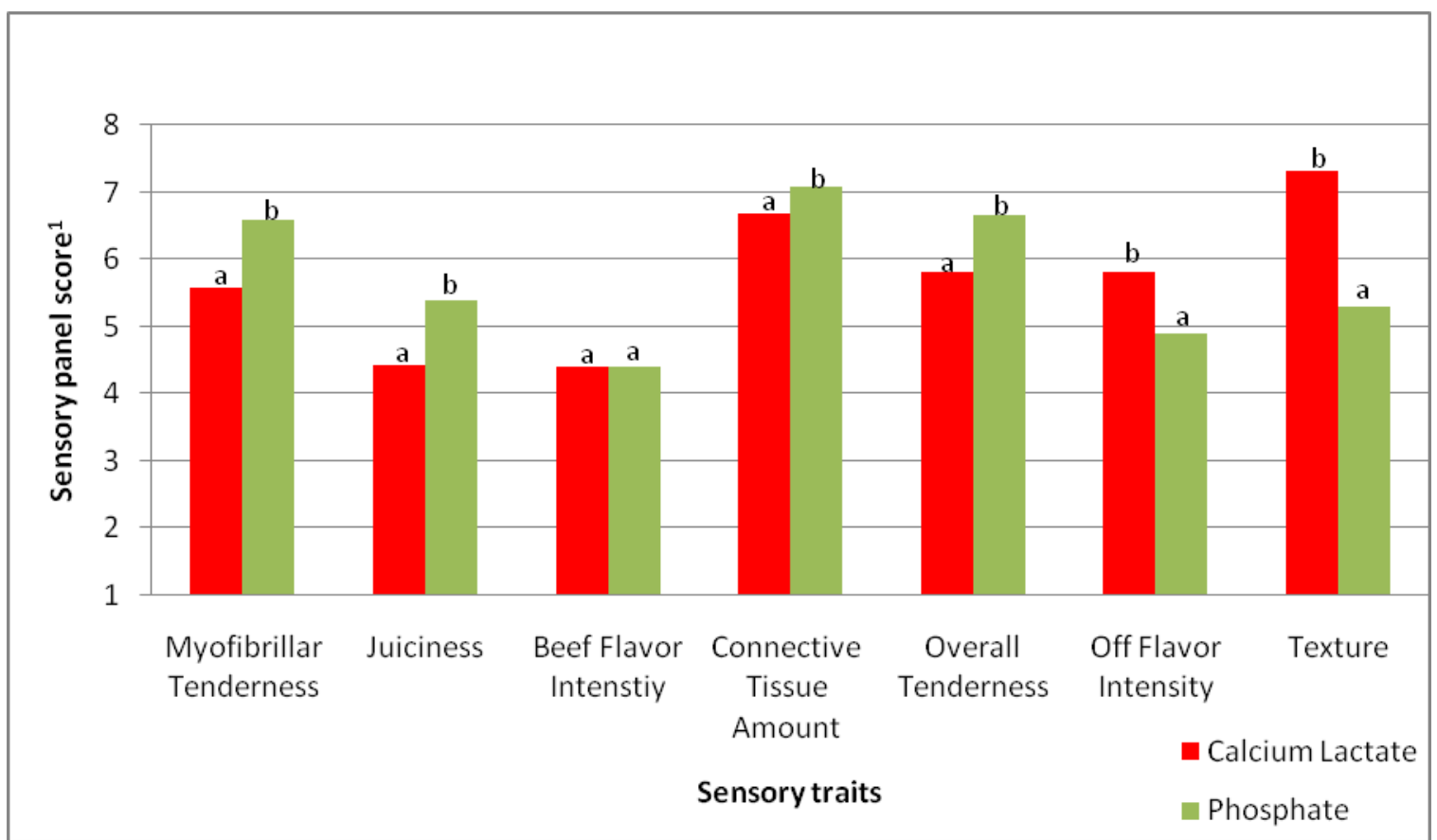

${ }^{1}$ myofibrillar and overall tenderness scale: $1=$ extremely tough, $4=$ slightly tough, $6=$ moderately tender, $8=$ extremely tender; juiciness scale: $1=$ extremely dry, $4=$ slightly dry, $6=$ moderately juicy, $8=$ extremely juicy; beef flavor intensity scale: $1=$ extremely bland, $4=$ slightly bland, $6=$ moderately intense, $8=$ abundant; connectivetissue amount scale: $1=$ abundant, $4=$ moderate, $6=$ traces, $8=$ none; off flavor intensity scale: $1=$ abundant, $4=$ moderate, $6=$ traces, $8=$ none; texture scale: $1=$ extremely abnormal, $4=$ slightly abnormal, $6=$ moderately normal, $8=$ extremely normal

abMeans within a sensory trait with different superscript letters differ $(P<0.05)$

Standard Errors: Myofibrillar tenderness $=0.125$; Juiciness $=0.130$; Beef flavor $=0.089$; Connective tissue $=0.117$; Overall tenderness $=0.126$; Off-flavors $=0.128$; Texture $=$ 0.141 


\section{Conclusion}

Literature comparing NF injection enhancement to traditional needle injection enhancement was, until now, not available. I investigated needle-free technology as a method of incorporating enhancement solutions into meat. My experiment also compared a phosphate and salt plus $\mathrm{K}$ lactate and rosemary solution to a Ca lactate plus rosemary solution for its effects on meat quality attributes. That too was a comparison for which there was little literature. Enhancement with the NF versus $\mathrm{N}$ injection did not have a detrimental effect on meat color and resulted in reduced cooking loss. However, NF injections resulted in more off-flavor intensity with the "soapy" descriptor being exclusive to the NF treatment. Abnormal textures described as "slick" or "mushy" were also associated with the NF injected steaks. I also noticed that the needle-free injector required substantially less enhancement solution to inject the same number of loins, which is a result of the needle-free injector wasting substantially less solution than the needle injector. Enhancement with the phosphate solution resulted in greater myofibrillar and overall tenderness, juiciness and cooking yield with less connective tissue, but it also caused more abnormal texture described as "gelatin" and more off-flavor intensity with most common descriptors of "salty" or "livery". Enhancement with either solution resulted in steaks with common off-flavor descriptors of salty, bitter, sour, acid, and metallic. Salty was the most common off-flavor descriptor, and it was more common to the phosphate treatment while all other descriptors were more common to the $\mathrm{Ca}$ lactate treatment. Injection enhancement with the NF technology may improve cooking yield; however, it is likely that it may also cause unusual texture and off-flavors. Injection enhancement of beef with a phosphate solution may be more beneficial at increasing tenderness, juiciness and cooking yields while decreasing connective tissue than enhancing with a Ca lactate solution, but more off-flavor intensity and abnormal texture are likely. 


\section{Literature Cited}

Baublits, R. T., F. W. Pohlman, A. H. Brown, Jr., and Z. B. Johnson. 2005. Effects of sodium chloride, phosphate type and concentration, and pump rate on beef biceps femoris quality and sensory characteristics. Meat Sci. 70:205-214.

Baublits, R. T., F. W. Pohlman, A. H. Brown, Jr., and Z. B. Johnson. 2006. Enhancement with varying phosphate types, concentrations, and pump rates, without sodium chloride on beef biceps femoris quality and sensory characteristics. Meat Sci. 72:404-414.

Grobbel, J. P., M. E. Dikeman, M. C. Hunt, and G. A. Milliken. 2008. Effects of different packaging atmospheres and injection-enhancement on beef tenderness, sensory attributes, desmin degradation, and display color. J. Anim. Sci. 86:2697-2710.

Hoffman, L. C. 2006. Sensory and physical characteristics of enhanced vs. nonenhanced meat from mature cows. Meat Sci. 72:195-202.

Knock, R. C., M. Seyfert, M. C. Hunt, M. E. Dikeman, R. A. Mancini, J. A. Unruh, J. J. Higgins, and R. A. Monderen. 2006a. Effects of potassium lactate, sodium chloride, and sodium acetate on surface shininess/gloss and sensory properties of injection-enhanced beef strip-loin steaks. Meat Sci. 74:319-326.

Koohmaraie, M. 1994. Muscle proteinases and meat aging. Meat Sci. 36:93-104.

Lawrence, T. E., M. E. Dikeman, M. C. Hunt, C. L. Kastner, and D. E. Johnson. 2003. Effects of calcium salts on beef longissimus quality. Meat Sci. 64(2):299-308.

Lawrence, T. E., M. E. Dikeman, M. C. Hunt, C. L. Kastner, and D. E. Johnson. 2004. Effects of enhancing beef longissimus with phosphate plus salt, or calcium lactate plus non-phosphate water binders plus rosemary extract. Meat Sci. 67:129-137.

Luchansky, J. B., A. C. Porto Fett, B. A. Shoyer, R. K. Phebus, H. Thippareddi, and J. E. Call. 2009. Thermal inactivation of Escherichia coli 0157:H7 in blade tenderized beef steaks cooked on a commercial open-flame gas grill. J. Food Prot. 72(7):1404-1411.

Molina, M. E., D. D. Johnson, R. L. West, and B. L. Gwartney. 2005. Enhancing palatability traits in beef chuck muscles. Meat Sci. 71: 52-61. 
Seyfert, M., M. C. Hunt, R. A. Mancini, K. A. Hachmeister, D. H. Kropf, J. A. Unruh, and T. M. Loughin. 2005. Beef quadriceps hot boning and modified atmosphere packaging influence properties of injection-enhanced beef round muscles. J. Anim. Sci. 83:686-693. 